\title{
PRÁTICAS EM BEM-ESTAR ANIMAL: ANIMAIS SILVESTRES, GRANDES E PEQUENOS ANIMAIS
}

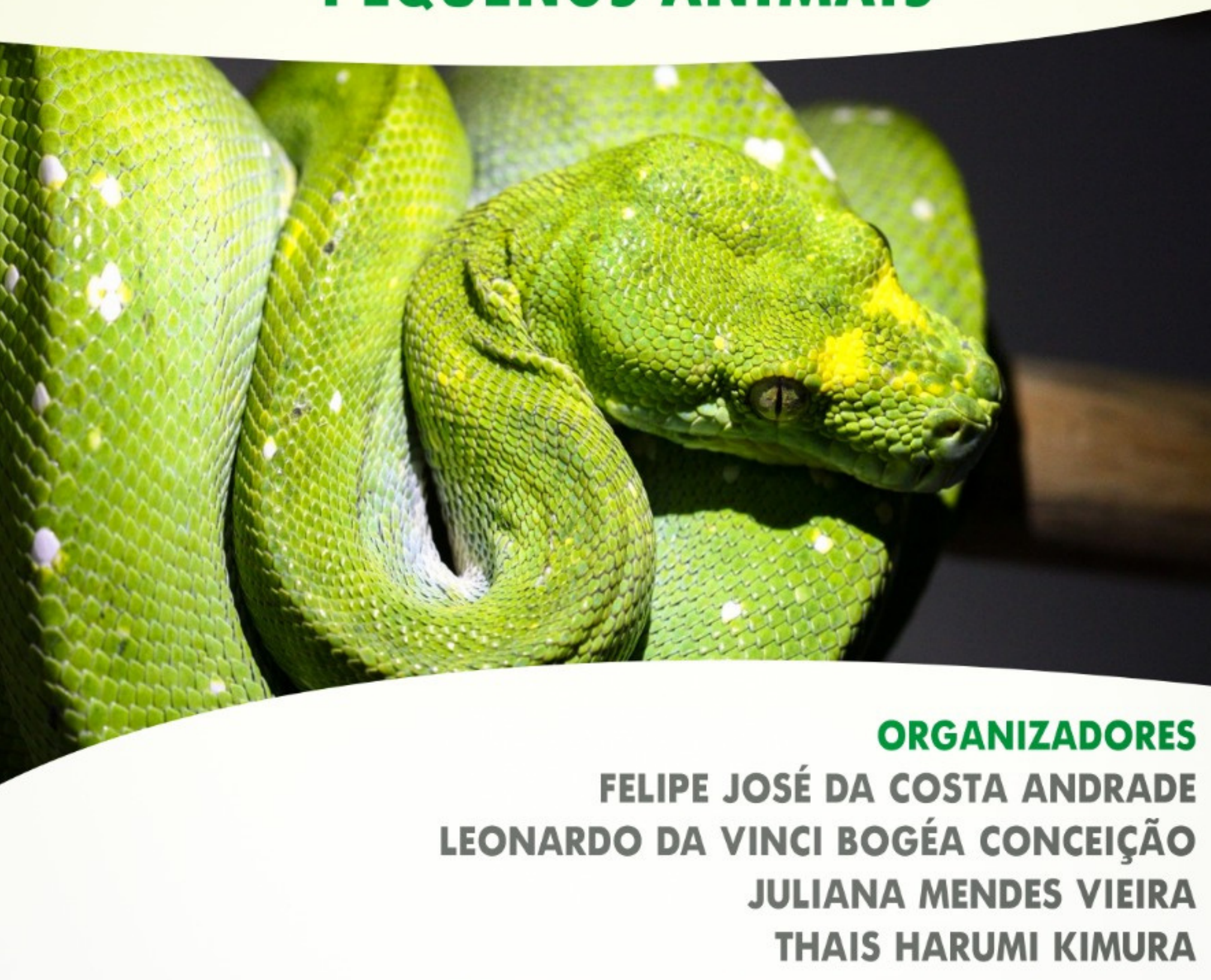

GABRIEL VINICIUS CARVALHO DE LUCENA 


\section{PRÁTICAS EM BEM-ESTAR ANIMAL: ANIMAIS SILVESTRES, GRANDES E PEQUENOS ANIMAIS}

\section{ORGANIZADORES}

FELIPE JOSÉ DA COSTA ANDRADE LEONARDO DA VINCI BOGÉA CONCEIÇÃO JULIANA MENDES VIEIRA THAIS HARUMI KIMURA GABRIEL VINICIUS CARVALHO DE LUCENA

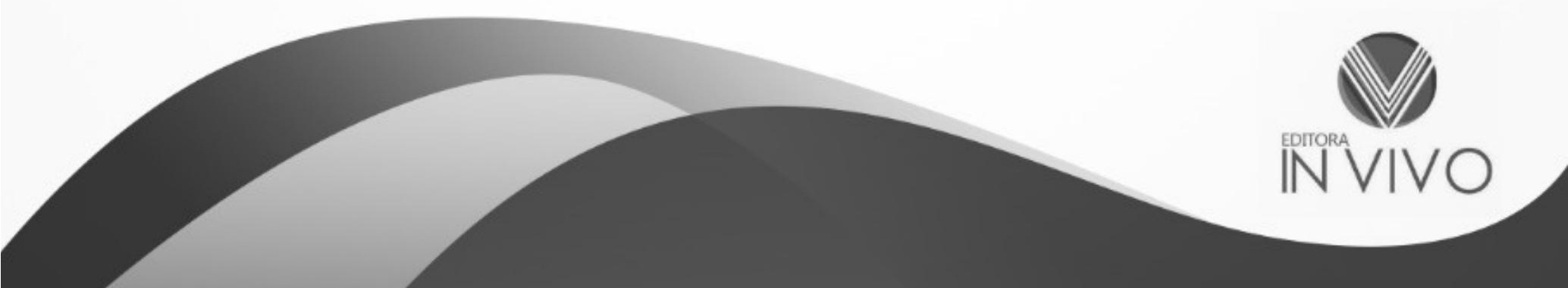




\title{
PRÁTICAS EM BEM-ESTAR ANIMAL: ANIMAIS SILVESTRES, GRANDES E PEQUENOS ANIMAIS
}

\author{
ANAIS DO SIMPÓSIO DE BEM-ESTAR ANIMAL (SIMBEA) \\ Organização: Grupo de Pesquisa Cangaceiro Vet
}

\author{
Felipe José da Costa Andrade \\ Leonardo Da Vinci Bogéa Conceição \\ Juliana Mendes Vieira \\ Thais Harumi Kimura \\ Gabriel Vinicius Carvalho de Lucena
}

(Organizadores) 
2022 by Editora In Vivo

Copyright (C) Editora In Vivo

Copyright do Texto C 2022 O autor

Copyright da Edição (C) 2022 Editora In Vivo

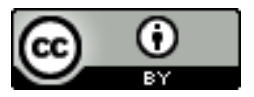

Esta obra está licenciada com uma Licença Creative Commons Atribuição 4.0 Internacional (CC BY 4.0).

O conteúdo desta obra e seus dados em sua forma, correção e confiabilidade são de responsabilidade

exclusiva dos autores. Permitido o download da obra e o compartilhamento desde que sejam atribuídos

créditos aos autores, mas sem a possibilidade de alterá-la de nenhuma forma ou utilizá-la para fins comerciais.

\section{Editor Chefe}

Dr. Everton Nogueira Silva

\section{Colégio de Ciências da Vida 1.1 Ciências Agrárias}

Dr. Aderson Martins Viana Neto Dra. Ana Paula Bezerra de Araújo

MSc. Edson Rômulo de Sousa Santos

Dr. Fágner Cavalcante P. dos Santos

MSc. Filomena Nádia Rodrigues Bezerra

Dra. Lina Raquel Santos Araújo

Dr. Luis de França Camboim Neto

MSc. Maria Emília Bezerra de Araújo

MSc. Yuri Lopes Silva

\subsection{Ciências Biológicas}

Dra. Antonia Moemia Lúcia Rodrigues Portela

\subsection{Ciências da Saúde}

Dra. Ana Luiza M. Cazaux de Souza Velho

Dr. Isaac Neto Goes Silva

Dra. Maria Verônyca Coelho Melo

MSc. Paulo Abílio Varella Lisboa

Dra. Vanessa Porto Machado

Dr. Victor Hugo Vieira Rodrigues

\section{Conselho Editorial}

2 Colégio de Humanidades

2.1 Ciências Humanas

Dra. Alexsandra Maria Sousa Silva

MSc. Francisco Brandão Aguiar

MSc. Julyana Alves Sales

2.2 Ciências Sociais Aplicadas

MSc. Cícero Francisco de Lima

MSc. Erivelton de Souza Nunes

MSc. Janaildo Soares Sousa

MSc. Karine Moreira Gomes Sales

Dra. Maria de Jesus Gomes de Lima

MSc. Maria Rosa Dionísio Almeida

MSc. Marisa Guilherme da Frota

3 Colégio de Ciências Exatas, Tecnológica

e Multidisciplinar

3.1 Ciências Exatas e da Terra

MSc. Francisco Odécio Sales

Dra. Irvila Ricarte de Oliveira Maia

3.2 Engenharias

MSc. Amâncio da Cruz Filgueira Filho

MSc. Gilberto Alves da Silva Neto

MSc. Henrique Nogueira Silva

Dr. João Marcus Pereira Lima e Silva

MSc. Ricardo Leandro Santos Araújo

Dados Internacionais de Catalogação na Publicação - CIP

A553p Andrade, Felipe José da Costa.

Práticas em bem-estar animal [livro eletrônico]: animais silvestres, grandes e pequenos animais./ Organizadores: Felipe José da Costa Andrade, ... [et al.]. Fortaleza: Editora In Vivo, 2022.

$66 \mathrm{p}$.

Bibliografia.

ISBN: 978-65-995500-6-5

DOI: $10.47242 / 978-65-995500-6-5$

1. Bem-Estar Animal. 2. Bem-Estar Animal - práticas. I. Título. II. Organizadores. 


\section{APRESENTAÇÃO}

A elaboração deste livro, que compreende um compilado de resumos científicos tem como objetivo a socialização de conhecimentos científicos, o incentivo à pesquisa e sua articulação com o ensino e a extensão, com vista a enriquecer a formação oferecida ao público interessado em Bem-Estar Animal. O livro foi extraído do Simpósio de Bem-Estar Animal (Simbea). Tal evento científico foi realizado no formato on-line e promovido pelo Grupo Cangaceiro Vet, nos dias 28, 29 e 30 de Junho de 2021, o evento contou com palestras de profissionais renomados, submissão de resumos, premiação dos melhores resumos aprovados, além do envio de material científico para leitura prévia dos participantes.

Está obra dispõe de uma coleção de resumos científicos submetidos e aprovados por uma banca avaliadora experiente constituída de Médicos Veterinários, Zootecnistas, Mestres e Doutores da área de Bem-Estar Animal. Os resumos abordam os mais diversos assuntos distribuídos dentro do Bem-Estar de Animais.

A comissão organizadora deseja que este livro seja uma obra proveitosa para os seu leitores e de fácil acesso para a comunidade cientifica que busca conhecimento na área de Bem-Estar Animal e suas demais vertentes. Desejamos a todos e a todas uma excelente leitura!

Felipe José da Costa Andrade Leonardo Da Vinci Bogéa Conceição 


\section{Organizadores}

Felipe José da Costa Andrade ${ }^{1}$

Leonardo Da Vinci Bogéa Conceição ${ }^{1}$

Juliana Mendes Vieira ${ }^{1}$

Thais Harumi Kimura ${ }^{1}$

Gabriel Vinicius Carvalho de Lucena ${ }^{1}$

${ }^{1}$ Medicina Veterinária - Universidade Federal do Piauí, campus Professora Cinobelina Elvas - UFPI/CPCE. Bom Jesus-PI.

Fotografia de capa e contracapa:

Gabriel Vinicius Carvalho de Lucena

Equipe Avaliadora:

Amilton Paulo Raposo Costa

Ana Luiza Guedes

Cynthia Cipreste

Danilo Maciel Duarte

Diogo Ramos Leal

Enore Massoni

Giulianna de Carvalho Ibrahim Obeid

Igor Oliveira Braga de Morais

Mariana de Oliveira Bonow

Renata Haddad Pinho

Natalia Philadelpho Azevedo 


\section{Sumário}

\section{SUMÁRIO}

Capítulo 1 - DOI: 10.47242/978-65-995500-6-5-1

Autores: Amanda Vitória Lima BARBOSA e Gilmara Miguel SOUZA.

A CANNABIS SATIVA COMO TERAPIA COMPLEMENTAR PARA A PROMOÇÃO DO BEM-ESTAR EM PACIENTES ONCOLÓGICOS - REVISÃO SISTEMÁTICA.

Capítulo 2 - DOI: 10.47242/978-65-995500-6-5-2

Autores: Tereza Cristina Raggi CAVALCANTE; Ingrid Nayara Duarte AZEVEDO; Yade Farias NUNES; Caroline de Brito FERREIRA; Maria Beatriz Medeiros Vale COSTA; Thays Raquel de Freitas BEZERRA; José Jurandi Nunes BATISTA JÚNIOR; e Josiany Souza Lins de VASCONCELOS.

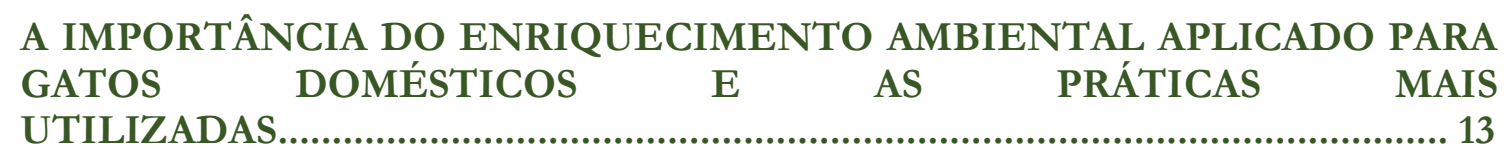

Capítulo 3 - DOI: 10.47242/978-65-995500-6-5-3

Autores: Gabrielle de Almeida ALVES; Ariane da Silveira MACHADO; Caroline Rezer da ROSA; Douglas Soares INCHAUSPE; e Deise Dalazen CASTAGNARA.

\section{A IMPORTÂNCIA DO ENRIQUECIMENTO AMBIENTAL PARA ANIMAIS EM ZOOLÓGICOS.}

Capítulo 4 - DOI: 10.47242/978-65-995500-6-5-4

Autores: Vitória Fernanda Ferreira da SILVA; Sandra Regina Pires de MORAES; Amanda Pereira RODRIGUES; Andressa Gabrielle Barbosa BARCELOS; Ivan Ricardo Matos ESPÍNDOLA; Thiago Augusto Costa MARINS; e Yasmin Silva de JESUS.

ACUPUNTURA: ORIGEM, BASES E APLICAÇÕES 16

Capítulo 5 - DOI: 10.47242/978-65-995500-6-5-5

Autores: Estela Silva ANTONIASSI; Maiara Gonçalves RODRIGUES; e Rodrigo OLIVINDO

ANÁLISE DE JULGADOS EM MEDICINA VETERINÁRIA: IMPLICAÇÕES NA EDUCAÇÃO MÉDICA.

Capítulo 6 - DOI: 10.47242/978-65-995500-6-5-6

Autores: Gabrielle de Almeida ALVES; Caroline Rezer da ROSA; Douglas Soares INCHAUSPE; e Deise Dalazen CASTAGNARA.

ASPECTOS GERAIS DE MANEJO PRIORIZANDO O BEM-ESTAR DE EQUINOS 
Capítulo 7 - DOI: 10.47242/978-65-995500-6-5-7

Autores: Rosecleer Rodrigues da SILVA e Rodrigo Fernando Gomes OLIVINDO.

AVALIAÇÃO SOBRE O PERFIL E PERSPECTIVA DOS TUTORES DE CÃES ATENDIDOS NO HOVET PÚBLICO - UNIDADE TATUAPÉ, SÃO PAULO SOBRE A CASTRAÇÃO PARA SANIDADE E BEM ESTAR

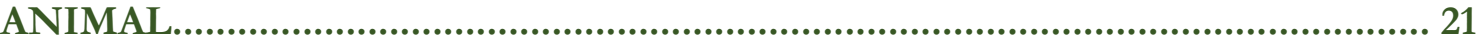

Capítulo 8 - DOI: 10.47242/978-65-995500-6-5-8

Autores: Bruna Gabriela da Costa MOREIRA; Laryssa Correia da SILVA; Pedro Luiz Ribeiro de VASCONCELOS; Rodrigo de Araújo CARDOSO; e Sandra Regina Pires de MORAES.

BEM-ESTAR DE BEZERRAS LEITEIRAS

Capítulo 9 - DOI: 10.47242/978-65-995500-6-5-9

Autores: Marília Gabryelle Guimarães de MACÊDO; Felipe José da Costa ANDRADE; Gabriel Almeida de Oliveira BEZERRA; Thais Harumi KIMURA; Gabriel Aquino ROCHA; e Delcio Almeida MAGALHÃES.

CONDICIONAMENTO OPERANTE POSITIVO EM ANIMAIS SILVESTRES COMO MÉTODO DE FACILITAR O MANEJO E PROMOVER O BEMESTAR 25

Capítulo 10 - DOI: 10.47242/978-65-995500-6-5-10

Autores: Thiago Viríssimo Rocha SILVA; Sandra Regina Pires de MORAES; Andressa Gabrielle Barbosa BARCELOS; e Paula Maria Santos FERREIRA.

ENRIQUECIMENTO AMBIENTAL COMO ESTRATÉGIA POSITIVA NA EXPRESSÃO DE COMPORTAMENTOS NATURAIS DOS FELINOS DOMICILIADOS 27

Capítulo 11 - DOI: 10.47242/978-65-995500-6-5-11

Autores: José Ricardo de SOUZA; Janaina Januário da SILVA; Tarcísio da Silva Santos JUNIOR; Sandra Helena Ramiro CORRÊA; e Brunna Ribeiro SILVA.

ENRIQUECIMENTO AMBIENTAL NO RECINTO DE JABUTIS-PIRANGA (Chelonoidis carbonária ) DO CENTRO DE MEDICINA E PESQUISA EM ANIMAIS SILVESTRES - CEMPAS, UFMT, CUIABÁMT 29

Capítulo 12 - DOI: 10.47242/978-65-995500-6-5-12

Autores: Letícia de Souza da SILVA; Suzy de Araújo ALBERNAZ; e Ailton Batista PEREIRA.

ENRIQUECIMENTO AMBIENTAL E FATORES QUE INFLUENCIAM OBEM-ESTAR DE SUÍNOS: REVISÃO BIBLIOGRÁFICA. 31 
Capítulo 13 - DOI: 10.47242/978-65-995500-6-5-13

Autor: Jassanael Pereira SIQUEIRA.

ENRIQUECIMENTO AMBIENTAL EM CÃES

Capítulo 14 - DOI: 10.47242/978-65-995500-6-5-14

Autora: Valéria Smith Neves e SANTOS.

\section{ENRIQUECIMENTO AMBIENTAL PARA GATOS DOMICILIADOS:}

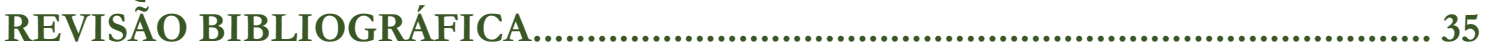

Capítulo 15 - DOI: 10.47242/978-65-995500-6-5-15

Autores: Yasmin Silva de JESUS; Sandra Regina Pires de MORAES; Lucas Dourado MATOS; Vitória Fernanda Ferreira da SILVA; e Ivan Ricardo Matos ESPÍNDOLA.

ENRIQUECIMENTO AMBIENTAL PARA VACAS LEITEIRAS 37

Capítulo 16 - DOI: 10.47242/978-65-995500-6-5-16

Autores: Yasmin Silva de JESUS; Victória Curvo ORMOND; Cely Marini Melo e OÑA; Janaina Januário da SILVA; e Isabela de Mantova CORRENTE.

ESTEREOTIPIAS E O BEM-ESTAR EM EQUINOS ESTABULADOS 39

Capítulo 17 - DOI: 10.47242/978-65-995500-6-5-17

Autores: Gabrielle Moura NASCIMENTO; Beatriz Domingues Bressan Lopes Guimarães VIDAL; Letícia Queiroz Landim de ALMEIDA; e Karolyne Moura NASCIMENTO.

IMPRINTING HUMANO E SUAS CONSEQUENNCIAS NO MANEJO DE AVES EM CATIVEIRO E DE VIDA LIVRE - REVISÃO BIBLIOGRÁFICA.

Capítulo 18 - DOI: 10.47242/978-65-995500-6-5-18

Autores: Thiago Augusto Costa MARINS; Sandra Regina Pires de MORAES; Andressa Gabrielle Barbosa BARCELOS; e Bruna Gabriela da Costa MOREIRA.

LOBO GUARÁ, DA VIDA SELVAGEM AO CATIVEIRO: AMBIENTE ENRIQUECIDO E BEM ESTAR.

Capítulo 19 - DOI: 10.47242/978-65-995500-6-5-19

Autora: Danielli Souza POLONI.

MANEJO CLÍNICO CAT-FRIENDLY: DO PREPARO AO ATENDIMENTO DO PACIENTE FELINO

Capítulo 20 - DOI: 10.47242/978-65-995500-6-5-20

Autores: Paula Maria Santos FERREIRA; Sandra Regina Pires de MORAES; Thiago Viríssimo Rocha SILVA; Andressa Gabrielle Barbosa BARCELOS.

MANEJO DE GATOS DOMÉSTICOS EXCLUSIVAMENTE 
Capítulo 21 - DOI: 10.47242/978-65-995500-6-5-21

Autora: Valéria Smith Neves e SANTOS.

MANEJO DE PORQUINHOS-DA-ÍNDIA COMO ANIMAIS DE ESTIMAÇÃO

Capítulo 22 - DOI: 10.47242/978-65-995500-6-5-22

Autores: Felipe José da Costa ANDRADE; Marília Gabryelle Guimarães de MACÊDO; Delcio Almeida MAGALHÃES; Gabriel Almeida de Oliveira BEZERRA; Gabriel Aquino ROCHA; e Thais Harumi KIMURA.

O USO DA CANNABIS SATIVA NO CONTROLE DE DOR E PROMOÇÃO DO BEM-ESTAR EM CÃES 51

Capítulo 23 - DOI: 10.47242/978-65-995500-6-5-23

Autores: Julia Pasa BRANDT; Vitória Souza DEBASTIANI; Isabelle Sá TEIXEIRA; e Deise Dalazen CASTAGNARA.

PAPEL DA CONSCIENTIZAÇÃO DE CRIANÇAS EM IDADE ESCOLAR NA PROMOÇÃO DE BEM ESTAR ANIMAL 53

Capítulo 24 - DOI: 10.47242/978-65-995500-6-5-24

Autora: Valéria Smith Neves e SANTOS.

PRÁTICAS PARA GARANTIR O BEM-ESTAR DE GATOS NO ATENDIMENTO VETERINÁRIO ............................................................. 55

Capítulo 25 - DOI: 10.47242/978-65-995500-6-5-25

Autores: Acácia da Vitória BARRETO; e Karina Carneiro SANTOS.

CRIAÇÃO INDOOR DE GATOS 57

Capítulo 26 - DOI: 10.47242/978-65-995500-6-5-26

Autores: Janaina Januário da SILVA; José Ricardo de SOUZA; Sandra Helena Ramiro CORREAA; Brunna Ribeiro SILVA; e Maria Gabriela Rossetti ROGERIO.

ABRIGOS COM DIFERENTES COBERTURAS PARA CATETOS (Pecari tacaju) DO CENTRO DE MEDICINA E PESQUISA EM ANIMAIS SILVESTRES (CEMPAS), UFMT, CUIABÁ-MT. 59

Capítulo 27 - DOI: 10.47242/978-65-995500-6-5-27

Autores: Gustavo Sá de CARVALHO; Liz Oliveira MENEZES; Maria Yasmim Florentino dos SANTOS; e Yade Farias NUNES.

USO DO ÓLEO DE CBD E THC (FULL SPECTRUM) COMO TERAPIA INTEGRATIVA NO TRATAMENTO DE SEQUELA DE CINOMOSE EM

CÃO: RELATO DE CASO. 61 


\section{A CANNABIS SATIVA COMO TERAPIA COMPLEMENTAR PARA A PROMOÇÃO DO BEM-ESTAR EM PACIENTES ONCOLÓGICOS - REVISÃO SISTEMÁTICA}

Amanda Vitória Lima BARBOSA e Gilmara Miguel SOUZA.

Área Temática: Medicina Integrativa

A prevalência de neoplasias em animais está aumentando ao longo dos anos, sendo lipoma, carcinoma de células escamosas, fibrossarcoma, hemangiosarcoma, lipossarcoma e adenoma mamário as mais comuns. Tratam-se de patologias onde o animal apresenta consideráveis efeitos colaterais e adversos à terapêutica, reação inflamatória intensa, dor crônica e nível de estresse elevado. Portanto, perdem a capacidade de regular o organismo e diminuindo a produção de anandamida (canabinóide endógeno), e assim precisam dos canabinóides exógenos para que a regulação seja feita. Descrito há milhares de anos, o uso da maconha para fins medicinais cresce a cada dia. Seus efeitos terapêuticos e até mesmo colaterais desejados são variados e podem beneficiar principalmente pacientes oncológicos. Os canabinóides possuem atividade antineoplásica (proteínas pro-apoptóticas, inibe a proliferação invasão e angiogênese), atividade antiemética, aliviam os sintomas como dor (ação protetora em neuropatia periférica e analgésico), aumentam o apetite, diminuem a ansiedade (relaxamento e controle do humor) e induzem a melhora do sono, além de controlar a reação inflamatória (inibe COX-2 e ROS). Reduzem as doses de opioides e outros medicamentos alopáticos. A superdosagem pode causar hipotensão, taquicardia, alucinação, disforia e depressão, por isso deve-se atentar a especificidade e individualidade de cada paciente. O objetivo deste trabalho é revisar os benefícios da utilização da Cannabis sativa para a promoção do bem-estar e qualidade de vida a animais com tumores neoplásicos. Estudos constataram o potencial antineoplásico dos canabinóides, incluindo D9tetrahidrocanabinol (D9-THC), agonistas sintéticos, endocanabinóides e inibidores de transporte ou degradação de endocanabinóides. Possuem efeitos antiproliferativos e pró-apoptóticos e inibem a neovascularização tumoral, migração de células cancerosas, adesão, invasão e metástase. Além disso, agem em diferentes etapas e diferentes tipos de câncer. A administração de $\Delta 9$ THC inibiu a migração induzida pelo fator de crescimento endotelial in vitro, bem como crescimento de tumor e metástase em modelos de camundongos. Os agonistas CB2 causaram a regressão do tumor e ativação de CB1 em camundongos com carcinoma do cólon reduziram o crescimento do tumor. Estudos realizados com o foco em terapia paliativa, indicaram melhoria de náuseas e vômitos induzidos pela quimioterapia e dores relacionadas ao câncer. A região do centro de controle do vómito, possui receptores CB1, que são ativados pelo D9-THC e demonstram efeitos antieméticos. Estes receptores também estão presentes no hipocampo, córtex e cerebelo e possuem características semelhantes ao sistema opioide. Assim, modulam o processamento nociceptivo. A Cannabis pode ser associada também a uma melhora no paladar e aumento do apetite, diminuindo a ocorrência de anorexia nesses animais; além da melhora do sono e diminuição da ansiedade. Conclui-se que a utilização da Cannabis sativa é viável e mostra-se eficaz na promoção de bem-estar e qualidade de vida em pacientes oncológicos.

Palavras Chaves: Oncologia; Cannabis sativa; Veterinária. 


\section{REFERÊNCIAS}

BLAKE Alexia.; WAN Bo Angela.; MALEK Leila. A selective review of medical cannabis in cancer pain management. Ann Palliat Med 2017.

BRAZ Vinicius. Ocorrência de neoplasias em animais selvagens no hospital veterinário da universidade federal de Uberlândia. UNIVERSIDADE FEDERAL DE UBERLÂNDIA, 2018.

COLMENARES Juan. Mascotas Y Cannabis Medicinal: Experiencias Desde La Práctica Clínica Y La Educación. Expo Mede Weed, vol. 1, nº 1, 2018.

MASSI Paola.; SOLINAS Marta.; CINQUINA Valentina.; PAROLARO Daniela. Cannabidiol as potential anticancer drug. British Journal of Clinical Pharmacology, 2012.

REPETTI Cláudia.; GIRIO Raul.; FRIOLANI Milena et al. Perspectives in veterinary medicine on the use of cannabinoids as complementary palliative therapy for pain in cancer patients. Ciência Rural, Santa Maria, vol. 49/02, 2019.

RIBEIRO Gabriela.; NERY Lara.; COSTA Ana.; et al. Potencial uso terapêutico dos compostos canabinoides - canabidiol e delta-9-tetrahidrocanabinol. Research, Society and Development, v. 10, n. 4, 2021.

TURGEMAN Ilit and BAR-SELA Gil. Cannabis Use in Palliative Oncology: A Review of the Evidence for Popular Indications. IMAJ, vol. 19, fev/2017. 


\section{A IMPORTÂNCIA DO ENRIQUECIMENTO AMBIENTAL APLICADO PARA GATOS DOMÉSTICOS E AS PRÁTICAS MAIS UTILIZADAS}

Tereza Cristina Raggi CAVALCANTE; Ingrid Nayara Duarte AZEVEDO; Yade Farias NUNES; Caroline de Brito FERREIRA; Maria Beatriz Medeiros Vale COSTA; Thays Raquel de Freitas BEZERRA; José Jurandi Nunes BATISTA JÚNIOR; e Josiany Souza Lins de VASCONCELOS.

Área Temática: Enriquecimento Ambiental

O enriquecimento ambiental consiste em um conjunto de modificações realizadas nas residências onde os felinos domésticos convivem com o intuito de assemelhar-se às características existentes na natureza, garantindo a expressão do seu comportamento natural, o que é necessário para o bem-estar físico e psicológico do animal, reduzindo o estresse ocasionado pelo ambiente cativo. Essas mudanças no ambiente e no manejo podem ser classificadas em cinco categorias diferentes, sendo caracterizadas pela forma em que são empregadas ao felino, sendo elas: cognitiva (que envolve a resolução de um quebra-cabeça alimentar, no qual o animal necessita solucionar o problema para obter a sua comida); alimentar (através de pequenas mudanças no tipo e modo de fornecimento dos alimentos para estimular o comportamento de caça, por meio da variação do horário das refeições e da exibição dos alimentos, os quais podem ser fornecidos dentro de brinquedos, espalhados na residência, suspensos ou escondidos); sensorial, estimulando a olfação (com a aplicação de ervas específicas, especiarias, óleos aromáticos e essências artificiais), a visão (por meio da adição de espelhos, brinquedos suspensos ou televisores) e a audição (com música clássica e sons semelhantes aos encontrados nas florestas, como o canto de pássaros, cachoeiras e balançar dos galhos das árvores); social (para obtenção de interações positivas entre humanos e animais respeitando as estruturas hierárquicas e comportamentais específicos da espécie felina) e estrutural (com a introdução de vegetações, objetos e móveis que possibilitem a realização de movimentos e atividades como escalar, saltar, afiar as unhas, rastejar, correr, entre outros).

Palavras Chaves: Bem-Estar; Comportamento; Felinos.

\section{REFERÊNCIAS}

CARPES, A. Z. 2015. Ferramentas para aplicação de enriquecimento ambiental para felinos cativos, $77 \mathrm{p}$.

DAMASCENO, J. 2018. Enriquecimento Ambiental para felinos em cativeiro: classificação de técnicas, desafios e futuras direções.

GUANDOLINI, G. C. 2009. Enriquecimento ambiental para gatos domésticos (Felis silvestris catus L.): A importância dos odores, 66p. 


\title{
A IMPORTÂNCIA DO ENRIQUECIMENTO AMBIENTAL PARA ANIMAIS EM ZOOLÓGICOS
}

\author{
Gabrielle de Almeida ALVES; Ariane da Silveira MACHADO; Caroline Rezer da ROSA; \\ Douglas Soares INCHAUSPE; e Deise Dalazen CASTAGNARA
}

\section{Área Temática: Enriquecimento Ambiental}

O enriquecimento ambiental é um processo dinâmico no qual, mudanças na estrutura e implantações de práticas de manejo (SGARBIEIRO, 2009) com estratégias físicas, sociais e sensoriais visam oferecer estímulos que possam aumentar o conforto e a capacidade de adaptação tanto fisiológica quanto psicológica do animal ao cativeiro (SIMÕ̃ES, 2009). Portanto, objetiva-se com esse resumo abordar a importância do enriquecimento ambiental para animais em zoológico. Sendo assim, na natureza os animais passam a maior parte do tempo à procura de alimentos, evitando predadores, procurando e disputando parceiros para acasalar e interagir, ou seja, com um ambiente dinâmico frente aos desafios diários. Já no cativeiro, os animais têm os seus alimentos fornecidos e são protegidos contra interações competitivas (MILITÃO, 2008). Desta forma, manter animais em cativeiro implica no dever ético de lhes proporcionar saúde física e psicológica. Sendo assim, o enriquecimento ambiental busca elevar o bem-estar de animais cativos, resultantes de modificações em seus recintos (FURTADO, 2006). Porém, é de suma importância ressaltar que o tipo de enriquecimento utilizado deve ser apropriado à espécie em questão, para garantir não só a segurança dos animais como do público, desta forma, existem diferentes técnicas utilizadas. Assim, o enriquecimento físico está relacionado à estrutura física do recinto, ambiente onde os animais estão inseridos. A intenção é deixar o recinto o mais semelhante possível ao habitat natural. Desta maneira são introduzidos poleiros e cordas para aves, tanques para hipopótamos, ursos, galhos e cordas no recinto dos macacos, entre outros exemplos (DOMINGUEZ, 2008). Além disso, o enriquecimento sensorial, segundo Dominguez (2008), consiste em explorar os cinco sentidos dos animais. Este tipo de enriquecimento pode ser feito com praticamente todos os animais, utilizando-se "trilhas de cheiro", com o intuito de aumentar o forrageamento, ou seja, a busca por alimento. É possível utilizar essências de limão, alecrim, canela, citronela e até mesmo fezes de animais de outros recintos. Assim, o enriquecimento cognitivo consiste em dispositivos mecânicos ("quebra-cabeças") para os animais manipularem e são maneiras de estimular suas capacidades intelectuais (DOMINGUEZ, 2008). Além disso, o enriquecimento social consiste na interação intraespecífica ou interespecífica que pode ser criada dentro de um recinto. Os animais têm a oportunidade de interagir com outras espécies que naturalmente conviveriam na natureza e/ou com indivíduos de mesma espécie (FZSP, 2013). O enriquecimento alimentar consiste em promover variações na alimentação dos animais, fazendo com que enfrentem desafios para a obtenção do alimento. O enriquecimento ambiental reduz o estresse, prevenindo o surgimento de comportamentos estereotipados ou promovendo o tratamento (eliminação ou redução) de tais comportamentos na vida cativa. Alivia os efeitos do stress na fisiologia sexual, facilitando a reprodução. Auxilia em possíveis reintroduções de espécies à natureza, pelo fato de interagirem em um ambiente mais complexo (MILITÃO, 2008). Outra grande importância do enriquecimento ambiental é no papel da conservação em zoológicos, pois ele permite ao visitante observar os animais se comportando da maneira mais próxima ao habitual, deixando-o assim mais satisfeito e interessado, o que facilita o trabalho de educação ambiental local (FZSP, 2013). 
Palavras Chaves: Enriquecimento Ambiental; Zoológico; Bem-Estar; Manejo.

\section{REFERÊNCIAS}

DOMINGUEZ, T. N. Enriquecimento Ambiental em Zoológicos - Instituto de Zootecnia - Universidade Federal de Viçosa - 2008.

FURTADO, M.O. Uso de Ferramentas Como Enriquecimento Ambiental Para MacacosPrego (Cebus Apella) Cativos. 2006. 77 p. Dissertação (Mestrado em Psicologia Experimental) - Instituto de Psicologia, Universidade de São Paulo, São Paulo, 2006.

MILITÃO, C. Enriquecimento Ambiental - Escola profissional agrícola. Portugal,2008.

SGARBIERO, T. Etograma como ferramenta de avaliação do enriquecimento ambiental para a conservação ex-situ de Ara macao (Linnnaeus, 1758) e Ara araruna (Linnnaeus, 1758) no zoológico municipal de Piracicaba-SP. Trabalho de conclusão de curso (Bacharelado em Ciências Biológicas) - Universidade de São Carlos, Sorocaba, 87 f. 2009.

SIMÕES, L. C. Influências do enriquecimento ambiental no comportamento e nível de cortisol em felídeos silvestres. Dissertação (Mestrado em Saúde Animal) - Universidade de Brasília, Brasília, 110 f., 2009. 


\section{ACUPUNTURA: ORIGEM, BASES E APLICAÇÕES}

Vitória Fernanda Ferreira da SILVA; Sandra Regina Pires de MORAES; Amanda Pereira RODRIGUES; Andressa Gabrielle Barbosa BARCELOS; Ivan Ricardo Matos ESPÍNDOLA; Thiago Augusto Costa MARINS; e Yasmin Silva de JESUS.

Área Temática: Medicina Integrativa

Partindo da Medicina Tradicional Chinesa (MTC) que abrange técnicas de massagem, exercícios respiratórios, orientações nutricionais e farmacopeia chinesa, a acupuntura (AP), técnica terapêutica empírica, busca estimular pontos específicos do corpo por meio de agulhas até atingir o equilíbrio ou a homeostase esperada. Tendo sua base filosófica nas teorias gerais do Taoísmo, que visa o equilíbrio entre homem e meio, a AP tenta restabelecer o que foi perdido, como lesões, estresse e demais desequilíbrios, a partir de partes específicas, essas que também podem ser usadas juntamente com a moxabustão, técnica responsável pela passagem de um bastão da erva Artemísia nos pontos. Nesse sentido, apesar de se mostrar eficaz em diferentes casos e até reconhecida pela Organização Mundial da Saúde como método recomendado para o tratamento de certas enfermidades, a AP é vista de forma equivocada por ter uma base filosófica, religiosa e mística. Todavia, a medicina veterinária, tanto internacional quanto nacional, reconheceu, recentemente, a prática como método eficaz no combate a dores, além de também poder ser uma possível substituta para fármacos com finalidades analgésicas, visando, assim, reduzir prescrições desnecessárias. Assim, por meio de estímulos de pontos precisos, disfunções reprodutivas, neurológicas, musculoesqueléticas, dermatológicas, dor, emergências anestésicas e discopatias podem ser tratadas com AP após diagnóstico adequado, pois a AP pode esconder ou alterar os sintomas clínicos. Portanto, devido as constatações a partir de relatos e estudos, a AP é cada vez mais recomendada como caminho viável na busca pela recuperação de animais.

Palavras Chaves: Equilíbrio, Recuperação, Prática.

\section{REFERÊNCIAS}

GLÓRIA, Isabela Pires. A utilização da acupuntura em medicina veterinária. 2017. Dissertação de Mestrado. Universidade de Évora.

CONTATORE, Octávio Augusto; TESSER, Charles Dalcanale; BARROS, Nelson Filicede. Medicina chinesa/acupuntura: apontamentos históricos sobre a colonização de um saber. História, Ciências, Saúde-Manguinhos [online]. 2018, v. 25, n. 3 [Acessado 1 Novembro 2021] , pp. 841-858. Disponível em: <https://doi.org/10.1590/S010459702018000400013>. ISSN 1678-4758. https://doi.org/10.1590/S010459702018000400013. 


\section{ANÁLISE DE JULGADOS EM MEDICINA VETERINÁRIA: IMPLICAÇÕES NA EDUCAÇÃO MÉDICA}

Estela Silva ANTONIASSI; Maiara Gonçalves RODRIGUES; e Rodrigo OLIVINDO

\section{Área Temática: Medicina Integrativa}

O Conselho Regional de Medicina Veterinária do Estado de São Paulo (CRMV SP), que possui como função a fiscalização profissional dos Médicos Veterinários e Zootecnistas, a fim de garantir o acesso público frente a processos ético-profissionais, o CRMV SP implantou o "Portal da Transparência" garantindo acesso público às estatísticas dos Processos Ético-Profissionais. Tal medida assegura à população claridade quanto a diversos aspectos imprescindíveis para uma Medicina Veterinária de Excelência, como por exemplo, perfil e caracterização geral de julgados. Este estudo teve como finalidade avaliar as características dos processos julgados cadastrados no CRMV SP, disponíveis no setor online do "Portal da Transparência" e discutir o impacto da necessidade de ampliação de conhecimentos deontológicos em Educação Médica, bem como debater a importância desta discussão em meio científico com relação às falhas do exercício profissional frente aos proprietários/tutores. Para tal, uma planilha para a sistematização de dados com 60 julgados em Medicina Veterinária em fiscalização, obtidos através do site "Portal da Transparência" do CRMV SP, foi elaborada cujo objetivo foi o de organizar conteúdo e discuti-lo. O Código de Ética foi elaborado para orientar e submeter os Médicos Veterinários a um instrumento normativo, visando o objetivo de padronizar condutas uniformes e garantir a excelência profissional, deste modo, todos os profissionais cadastrados no CRMV SP podem responder judicialmente, caso apresente uma conduta imprópria visto o Código de Ética, culminando em possíveis penalizações de caráter de responsabilidade subjetiva ou objetiva. Os resultados apresentam um crescimento exponencial na quantidade de violação, sendo que em 2015 apenas 9 profissionais foram apenados e em 2019 obteve-se um total de 92 denúncias de caráter subjetivo, correspondendo a um aumento de $922 \%$ com relação à 2015 . As infrações ocorreram em sua maior parte em Pet Shops (7\%), Hospitais Veterinários (7\%) e outros $(14 \%)$ e ocorrem em $65,5 \%$ por parte dos tutores. Esses dados não elucidam, necessariamente, o aumento de ocorrências antiéticas, mas sim, o aumento da visibilidade da população frente as condutas profissionais dos Médicos Veterinários e Zootecnistas, isto também pode estar intimamente relacionado ao aumento crescente de animais situação de familiarização ao longo dos últimos dez anos. Diversos fatores estão inclusos no aumento da quantidade de denúncias frente às infrações, como, conscientização da população, visibilidade da mídia e até mesmo precarização no setor de saúde pública. Em literatura, não foram encontrados trabalhos que comprovem os motivos das denúncias subjetivas, deste modo, propõe-se como objetivo secundário debater a importância desta discussão em meio científico com relação às falhas do exercício profissional frente a proprietários/tutores que buscam atendimento com seus pets.

Palavras Chaves: Portal Transparência; Ética; Educação Médica; Denúncias. 


\section{REFERÊNCIAS}

BITTENCOURT, A.G.V. et al. Análise do erro médico em processos éticosprofissionais: Implicações na educação médica. Revista Brasileira de Educação Médica, 31(3), p.223 - 228, 2007.

CONSELHO FEDERAL DE MEDICINA VETERINÁRIA. Resolução $\mathbf{n}^{\mathbf{0}} \mathbf{1 1 3 8}$, de 16 de dezembro de 2016. Aprova o Código de Ética do Médico Veterinário. Disponível em: http://portal.cfmv.gov.br/uploads/RESO $\% 2011382016 \% 20 \mathrm{C} \% \mathrm{C} 3 \% \mathrm{~B} 3 \mathrm{digo} \% 20 \mathrm{de} \% 20 \% \mathrm{C} 3 \% 89$ tica $\% 20 \mathrm{do} \% 20 \mathrm{M} \% \mathrm{C} 3 \%$ A 9 dico $\% 20$ Veterin $\% \mathrm{C} 3 \%$ A1rio.pdf. Acesso em: Jun/2020.

LOSS, L.D. et al. Posse responsável e conduta de proprietários de cães no município de Porto Alegre - ES. Acta Veterinária Brasilica, 6(2), p. 105 - 111, 2012.

MAHUAD, L.C.N.E. \& MUHUAD, C. Imputação da responsabilidade civil: responsabilidade objetiva e subjetiva. Disponível em: http://www.tjsp.jus.br/download/EPM/Publicacoes/ObrasJuridicas/rc2.pdf?d=636680468024086265. Acesso em: Jun/2020.

PORTAL DA TRANSPARÊNCIA. Conselho Regional de Medicina Veterinária do Estado de São Paulo - CRMV SP. Disponível em: https://www.crmvsp.gov.br/site/transparencia_pub_fiscalizacao.php?a24_tipo=2. Acesso em: Jun/2020. 


\section{ASPECTOS GERAIS DE MANEJO PRIORIZANDO O BEM-ESTAR DE EQUINOS}

Gabrielle de Almeida ALVES; Caroline Rezer da ROSA; Douglas Soares INCHAUSPE; e Deise Dalazen CASTAGNARA.

\section{Área Temática: Manejo para Bem-Estar}

A definição do termo "bem-estar" não é simples. Broom (1986) definiu-o como "o estado de um indivíduo relacionado às suas tentativas de se adaptar ao ambiente". Já Malinowski (2004) considerou essa ciência como o estudo das reações psicofisiológicas dos animais ante aos estímulos externos gerados pelo homem. Portanto, objetiva-se com esse trabalho descrever os principais cuidados no manejo geral para proporcionar bem-estar aos equinos. Sendo assim, ao menosprezar as condições de bem-estar, o animal geralmente entra em um quadro de estresse no qual o inibe de exercer seu adequado desempenho (MCGREEVY \& MCLEAN,2010). Desta forma, a expressão do comportamento de um equino é resultado do sistema de criação, da qualidade do ambiente físico no qual o animal é criado, além da característica comportamental do próprio indivíduo (LEWIS, 2000). Em relação ao bemestar dos equinos, é significativo destacar que são cientificamente comprovados como seres sencientes, ou seja, compreendem o que se passa ao seu redor e possuem a capacidade de experimentar sentimentos bons ou ruins (Broom e Molento, 2004). Naturalmente, os equinos passam a maior parte do seu dia se alimentando (60-70\% das horas do dia) (BIRD; 2004; CINTRA, 2011; CORRÊA, 2019). A alimentação e o trabalho devem ser realizados seguindo seus horários programados e as alterações devem interferir o mínimo possível nas demais atividades (BIRD, 2004). Além de um volumoso de qualidade, é essencial fornecer aos cavalos, água limpa e fresca, alimentos concentrados (grãos e ração) e suplementos, respeitando as exigências nutricionais de cada categoria. Além disso, a ambiência envolve as instalações e o que são utilizadas nestas; elas devem levar em consideração as características físicas e o comportamento dos animais, bem como o conforto que será proporcionado, a segurança e a higiene (BIRD, 2004). Broom e Molento (2004) definem saúde como o completo estado de bem-estar físico e emocional, acompanhado da ausência de injúrias e doenças. Sendo assim, diversas situações ligadas ao estresse levam ao comprometimento da saúde física e mental dos equinos. O manejo nutricional inadequado de equinos confinados é uma das principais causas da saúde comprometida, sendo comum o aparecimento de cólicas, estereotipias, problemas dentários, má condição corporal, além de vícios orais e motores (LEME et al., 2017; CORRÊA, 2019). Assim, um bom manejo alimentar pode reduzir o surgimento de problemas de saúde relacionados com a alimentação. Desta forma, para garantir que o estado mental esteja em perfeito equilíbrio, cabe ao homem proporcionar aos equinos um ambiente com boas condições de qualidade de vida. Ou seja, prover alimento e água de boa qualidade e quantidade; instalações seguras, confortáveis e limpas; um manejo alimentar e sanitário que proporcione boa saúde; e tratá-los de forma que se sintam confortáveis e livres para expressar seu comportamento natural. Todos estes aspectos vão garantir que o animal desenvolva e mantenha um bom estado mental (BROOM e MOLENTO, 2004, 2011; MELLOR, 2016, 2017).

Palavras Chaves: Manejo; Bem-Estar; Equinos; Comportamento. 


\section{REFERÊNCIAS}

BIRD, J. Cuidado Natural del Caballo. Acanto, 2004, 206p.

BROOM, D. M.; FRASER, A. F. Comportamento e bem-estar de animais domésticos. 4. ed. Barueri: Manole, 2010, 421 p.

BROOM, D. M. e MOLENTO, C. F. M. "Bem-estar animal: conceitos e questões relacionadas - Revisão". Archives of Veterinary Science, v. 9, n. 2, p. 1-11, 2004.

LEME, D. P. et al. Management, health, and abnormal behaviors of horses: A survey in small equestrian centers in Brazil. Journal of Veterinary Behavior, v. 9, p.114-118,2014.

LEME, D. P. et al. Manual de Boas-Práticas de Manejo em Equideocultura. Brasil. Ministério da Agricultura, Pecuária e Abastecimento. Secretaria de Mobilidade Social, do Produtor Rural e Cooperativismo. Brasília: MAPA/ACE/CGCS,50p,2017.

LEWIS, L. D. Alimentação e cuidados do cavalo. São Paulo: Livraria ROCA, 1985.248p.

LEWIS, L. D. Nutrição clínica equina: alimentação e cuidados. São Paulo, Ed. Roca, 2000. $710 \mathrm{p}$.

MALINOWSKI, K. The horse industry's responsibility to animal welfare. 2004.

MCGREEVY, P. D.; MCLEAN, A. N.; WARREN-SMITH, A. K.; WARAN, N.; GOODWIN, D. Defining the terms and processes associated with equitation. Proceedings of the 1st International Equitation Science Symposium, August 2005. Broadford, Victoria, Post-Graduate Foundation in Veterinary Science, Sydney, 10-43.

MCGREEVY, P. Equine behavior: a guide for veterinarians and equine scientists. Londres: Saunders, 2004. 357p. 


\title{
AVALIAÇÃO SOBRE O PERFIL E PERSPECTIVA DOS TUTORES DE CÃES ATENDIDOS NO HOVET PÚBLICO - UNIDADE TATUAPÉ, SÃO PAULO - SOBRE A CASTRAÇÃO PARA SANIDADE E BEM ESTAR ANIMAL
}

\author{
Rosecleer Rodrigues da SILVA e Rodrigo Fernando Gomes OLIVINDO.
}

\section{Área Temática: Manejo para Bem-Estar}

Segundo a Organização Mundial da Saúde Animal (OIE), considera-se um bom estado de bem-estar se o animal estiver saudável, confortável, bem nutrido, capaz de expressar seu comportamento natural, livre de dores, medo e angústia. Algumas medidas podem ser adotadas para favorecer o bem-estar de cães, como a castração que auxilia na sanidade por proporcionar a prevenção de doenças, além de auxiliar no controle populacional. Portanto, esse estudo teve como objetivo avaliar o motivo no qual os tutores de cães atendidos no HOVET Público - Unidade Tatuapé, São Paulo - castram seus cães afim de ampliar os conhecimentos sobre saúde animal visando o bem-estar. A pesquisa foi realizada com 500 tutores, por meio de questionários, em um período de cinco dias. Para verificar a influência do sexo, idade e escolaridade do tutor em relação a decisão e aos benefícios da castração para saúde, bem como a influência do sexo e raça do animal na tomada da decisão, realizou-se o teste estatístico qui-quadrado $\left(\mathrm{X}^{2}\right)$ com nível de significância de 5\%. Entre as mulheres, 190 $(52,5 \%)$ castraram seus animais e $172(47,5 \%)$, não. O resultado foi semelhante entre os homens, pois $70(50,7 \%)$ castraram e 68 (49,3\%), não. Em relação a faixa etária, 23 pessoas eram jovens; 69 idosos; e 408 adultas. Dentro desses grupos, obteve-se as seguintes porcentagens de animais castrados: 43,5\%; 52,2\%; e 52,5\%, respectivamente. Quanto a escolaridade observou-se uma influência significativa, pois $113(64,6 \%)$ pessoas com ensino superior castraram seus animais, enquanto as porcentagens entres as pessoas com ensino fundamental e médio foi de $44,8 \%$ e $45,1 \%$, respectivamente. Sobre o motivo da castração, o mais citado foi "evitar filhotes", sendo mencionado por $77(29,6 \%)$ pessoas, contribuindo positivamente para o bem-estar, pois o controle populacional evita o abandono que gera medo, sofrimento, fome, sede e falta de cuidados; o segundo foi "evitar doenças", mencionado por $71(27,3 \%)$ pessoas sendo que, apenas, $14(19,7 \%)$ souberam citar, pelo menos, uma doença. Dentre os tutores que realizaram a castração terapêutica, 37 ( $72,5 \%)$ eram tutores de fêmeas relatando, como motivo: neoplasia mamária, piometra, pseudociese e distocia, e $14(27,5 \%)$ eram tutores de machos sendo relatado criptorquidismo, neoplasia testicular, e hiperplasia prostática benigna. Estes números indicam que a falta de conhecimento sobre sanidade e profilaxia podem resultar em dor e sofrimento para os animais devido afecções que poderiam ser evitadas. No grupo das pessoas que não castraram, $32(13,3 \%)$ relataram que não tinham conhecimento e se arrependem, pois o animal apresentou problemas decorrentes da ausência do procedimento. Esse levantamento constatou que ainda é baixo o número de informações sobre sanidade e os benefícios da castração, além de constatar que sua ausência trará, em algum momento da vida, dor e angústia, contrariando os princípios do bem-estar.

Palavras Chaves: Prevenção; Benefícios; Saúde Animal. 


\section{REFERÊNCIAS}

BROOM, D.M.; FRASER A.F. Comportamento e bem-estar de animais domésticos. Editora Manole, $4^{\mathrm{a}}$ edição, 2010.

BROOM, D.M.; MOLENTO, C.F.M. Animal welfare: concept and related issues - Review. Archives of Veterinary Sciense, v. 9, n. 2, p. 1-11, 2004.

OIE. Introdução às recomendações para o bem-estar animal. Código Terrestre de Saúde Animal, sessão 7, capítulo 7.1, 2017.

OLIVINDO, R.F.G; SILVA, R.R.; MATIAS, A.; ALEXANDRINO, C.; BERNARDINO M. Perfil e perspectiva dos tutores de cães, do Hovet Público, sobre os benefícios da castração. Pubvet, v. 15, n. 11, p. 180, 2021. 


\section{BEM-ESTAR DE BEZERRAS LEITEIRAS}

Bruna Gabriela da Costa MOREIRA; Laryssa Correia da SILVA; Pedro Luiz Ribeiro de VASCONCELOS; Rodrigo de Araújo CARDOSO; e Sandra Regina Pires de MORAES.

\section{Área Temática: Manejo para Bem-Estar}

A produção primária de leite em 2019 gerou $\mathrm{R} \$ 35$ bilhões e a indústria de derivados gerou $\mathrm{R} \$ 70,9$ bilhões ficando atrás da indústria de derivados da carne, café, chá e cereais. No decorrer das últimas duas décadas a produção de leite aumentou quase $80 \%$ utilizando praticamente o mesmo número de vacas ordenhadas. A reestruturação que a cadeia produtiva vem passando, saindo de um modelo extrativista para outro mais competitivo, consequentemente provoca a intensificação da atividade. Além da corrida por tecnologia, genética e nutrição, é cada vez mais importante melhorar as questões ligadas ao bem-estar animal. A adoção de práticas de bem-estar animal nas propriedades leiteiras aliado a outros fatores de produção proporcionam melhores desempenhos. No período do nascimento ao desmame, considerado o mais crítico, as bezerras não têm recebido a atenção necessária dos produtores. A falta de atenção da bezerrada se dá por não gerarem renda imediata, mas é preciso lembrar que elas serão as futuras produtoras das propriedades. Quando os animais são separados de suas mães é indicado no aleitamento uma dieta líquida, podendo ser leite in natura ou sucedâneos lácteos. Entre os métodos de aleitamento artificial, as mamadeiras e os baldes são os mais empregados. Entretanto, o uso de mamadeiras possibilita aos bezerros demonstrarem o comportamento mais próximo ao natural, a sucção, causando maior salivação. A saliva contém lipase salivar que inicia o processo de digestão de gordura, quando a lipase salivar está presente em baixos níveis a gordura passa intacta pelo abomaso. Pelo fato de que os bezerros são desmamados muito cedo, a relação homem-animal se torna um determinante no bem-estar dos animais, visto que o tratador está diretamente ligado com os reflexos de comportamento dos animais, podendo esses serem reflexo negativos que causam medo, estresse e logo um aumento do cortisol, ou reflexos positivos de animais mais calmos e mansos. Em diversas propriedades os animais desmamados são colocados em gaiolas ou piquetes individuais, negando seu instinto natural de animais arrebanhados. Nesse sentido é necessário que se faça a escolha do correto sistema de criação das bezerras leiteiras em que as instalações devem proteger esses indivíduos contra-ventos, altos índices de umidade e do calor, além de proporcionar aos bezerros espaço físico e com acesso ao pasto para se locomoverem e desenvolverem o comportamento de pastejo, o que contribui para o desenvolvimento ruminoreticular tornando-os ruminantes funcionais. As propriedades devem adotar um sistema de criação que permita a expressão de seus comportamentos naturais evitando estereotipias. A socialização dos bezerros garante animais adultos mais doceis no rebanho, facilitando o manejo dos animais.

Palavras Chaves: Prevenção; Benefícios; Saúde Animal.

\section{REFERÊNCIAS}

MAGALHÃES, C.B.; et al. Influência do sistema de cria no bem-estar e comportamento de bezerros leiteiros durante a fase de cria - Revisão de literatura. Revista Electrónica de Veterinária. 
PEREIRA, L.C.A.; OLIVEIRA, A.F.M. 2020. Bem-estar de bezerros durante o aleitamento e a desmama em diferentes sistemas de criação: Revisão. Revista Publicações em Medicina Veterinária e Zootecnia.

SILVA, D.F.; et al. Bem-estar na bovinocultura leiteira: Revisão. Revista Publicações em Medicina Veterinária e Zootecnia. 


\title{
CONDICIONAMENTO OPERANTE POSITIVO EM ANIMAIS SILVESTRES COMO MÉTODO DE FACILITAR O MANEJO E PROMOVER O BEM-ESTAR
}

\author{
Marília Gabryelle Guimarães de MACÊDO; Felipe José da Costa ANDRADE; Gabriel \\ Almeida de Oliveira BEZERRA; Thais Harumi KIMURA; Gabriel Aquino ROCHA; e \\ Delcio Almeida MAGALHÃES.
}

Área Temática: Manejo para Bem-Estar

O condicionamento operante por reforço positivo baseia-se em estimular um animal a realizar determinado comando em troca de recompensa. Sendo assim, o fundamento dessa técnica especifica que o comportamento de um indivíduo é determinado por suas consequências, se a consequência do ato for boa a frequência de execução do comportamento tende a aumentar. Logo, esse método é muito utilizado em animais silvestres com o objetivo de treiná-los a cooperarem voluntariamente durante a realização de procedimentos veterinários e de manejo. Objetiva-se no presente trabalho apresentar o condicionamento operante positivo como uma ferramenta facilitadora do manejo de animais silvestres de cativeiro e sua utilidade na promoção do bem-estar. A coleta de dados foi realizada no mês de junho de 2021 por meio da plataforma Google Acadêmico. Dessa busca, foram selecionados 9 trabalhos científicos sobre condicionamento operante em animais silvestres. O estudo promovido por Carpi (2015), realizado com 7 onças pintadas (Panthera onca), demonstrou que o condicionamento operante positivo tem potencial para melhorar a qualidade de vida de animais em cativeiro, em decorrência da modificação do padrão comportamental dos indivíduos, elevando a expressão de comportamentos associados ao bem-estar e diminuindo a inatividade. O trabalho de Oliveira (2017) foi procedido com uma girafa (Giraffa camelopardalis) e evidenciou a eficácia da técnica na aceitação de manipulação, aumentando a segurança na realização de procedimentos de manejo, além de proporcionar um relacionamento mais próximo com os tratadores e, portanto, uma melhoria na qualidade de vida do animal, uma vez que permite a identificação precoce e prevenção de enfermidades. Já Emer (2015) realizou o treinamento, dessa vez com 6 pítons birmanesa selvagens (Python molurus bivittatus) e constatou a possibilidade de condicionamento da espécie além de facilitar o ajuste desses animais ao ambiente cativo. No trabalho de Ferraz et al (2013) 24 saguis-detufo-branco (Callithrix jacchus) foram condicionados a fornecerem amostras de salivas, como resultado obtiveram redução do estresse e do uso de fármacos, melhoria no enriquecimento ambiental, aumento da segurança no manejo, maior flexibilidade e confiança na coleta de amostras. Resultados parecidos foram vistos em Manacero (2016) com 18 saguis-de-tufobranco e saguis-de-tufo-preto (Callithrix sp). Por sua vez, Holden et al (2016) condicionaram rinocerontes a apresentarem o solado das patas permitindo a inspeção e tratamento. $\mathrm{O}$ autor relata ainda a execução de diversos procedimentos sem necessitar imobilização ou causar estresse, além de fortalecer a confiança entre animais-equipe, contribuiu para o enriquecimento ambiental e complexidade do ambiente. Weiss e Wilson (2003) condicionaram 4 tartarugas-gigante-de-aldabra (Geochelone gigantea) para facilitar a coleta sanguínea e outros procedimentos de manejo e os resultados mostraram que a técnica diminuiu o estresse animal durante a execução desses. Nery et al (2012) utilizou a técnica com um espécime de lobo-guará (Chrysocyon brachyurus) para facilitar os procedimentos de manejo, como manipulação da vulva, apresentando resultados satisfatórios. Dessa forma, $100 \%$ dos trabalhos evidenciaram a utilidade do condicionamento operante positivo como mecanismo facilitador de manejo e promotor do bem-estar. Espera-se com esse estudo que 
mais trabalhos sejam realizados com objetivo de aperfeiçoar o manejo e bem-estar de animais silvestres em cativeiro.

Palavras Chaves: Animais ex situ; Treinamento Operante; Comportamento; Reforço Positivo

\section{REFERÊNCIAS}

EMER, S.A. et al. Predators in training: operant conditioning of novel behavior in wild Burmese pythons (Python molurus bivitattus). Animal Cognition, [s. 1.], v. 18, p. 269-278, 2015.

FERRAZ, M.C. et al. The use of operant instrumental conditioning with positive reinforcement for collection of saliva from marmosets (Callithrix jacchus) for research purposes. Revista de Etologia, [s. 1.], v. 12, n.1/2, p. 25-28, 2013.

GARCIA, L.C.F. Contribuição do condicionamento para o bem-estar de onças-pintadas (Panthera onca) em cativeiro. Orientador: Francisco Ernesto Moreno Bernal. 104 p. Tese (Doutorado em Ciências Animais) - Faculdade de Agronomia e Medicina Veterinária, Universidade De Brasília, Brasília - DF, 2015.

HOLDEN, M.D. et al. Operant-conditioning programme for White rhinoceros, Black rhinoceros and Indian or Greater one-horned Asian rhinoceros. International Zoo Yearbook, [s. 1.], v. 40, p. 144-149, 2006.

MANACERO, R.B. O condicionamento operante como ferramenta visando o bem-estar de calitriquídeos cativos e os benefícios da associação da homeopatia. Orientadora: Cidéli de Paula Coelho. 79 p. Dissertação (Pós-graduação em Medicina Veterinária e Bem-estar Animal) - Faculdade de Medicina Veterinária, Universidade Santo Amaro, São Paulo - SP, 2016.

NERY, E. et al. Condicionamento operante em loba-guará adulta (Chrysocyon Brachyurus). In: Simpósio de Produção Acadêmica, IV, 2012, Viçosa. Anais, Viçosa-MG: Anais IV SIMPAC, v. 4, n. 1, p. 127-130, 2012.

OLIVEIRA, T.V. Dessensibilização e condicionamento operante de girafa (Giraffa camelopardalis) no Zooparque Itatiba - São Paulo. Orientado: Fabrício Braga Rassy. 21 p. Trabalho de Conclusão de Curso (Pós-graduação em Comportamento Animal) - Centro Universitário da Fundação de Ensino Octávio Bastos, São Paulo - SP, 2017.

WEISS, E.; WILSON, S. The Use of Classical and Operant Conditioning in Training Aldabra Tortoises (Geochelone gigantea) for Venipuncture and Other Husbandry Issues. Journal Of Applied Animal Welfare Science, [s. 1.], v. 6, n. 1, p. 33-38, 2003. 


\title{
ENRIQUECIMENTO AMBIENTAL COMO ESTRATÉGIA POSITIVA NA EXPRESSÃO DE COMPORTAMENTOS NATURAIS DOS FELINOS DOMICILIADOS
}

\author{
Thiago Viríssimo Rocha SILVA; Sandra Regina Pires de MORAES; Andressa Gabrielle \\ Barbosa BARCELOS; e Paula Maria Santos FERREIRA.
}

Área Temática: Enriquecimento Ambiental

Os felinos vêm sendo cada vez mais adotados como animais de companhia, por serem, por dito popular, independentes, solitários, autossuficientes e não demandarem muita atenção. $\mathrm{E}$ de fato, essas são algumas características que se fazem presentes em grande parte dos gatos domiciliados, o que não se leva em consideração é que esse tipo de comportamento só é relatado devido os felinos ainda não serem 100\% domesticados permitindo que ainda expressem alguns comportamentos ancestrais e os mesmos nem sempre são desejáveis como os popularmente descritos. Atualmente, os principais comportamentos indesejáveis relatados pelos tutores são: micção e defecação em locais inadequados, vocalização excessiva, danificação de móveis por arranhadura e agressividade. Esses comportamentos devem ser muito bem entendidos e diferenciados de outros sinais semelhantes de possíveis patologias, como afecções do trato urinário que podem levar a mudança de comportamento, que não necessariamente está relacionada com problemas comportamentais da espécie. Como estratégia de minimizar esses comportamentos, emprega-se a utilização de alguns fármacos alopáticos, como os antidepressivos tricíclicos e os inibidores seletivos de serotonina, os quais devem ser constantemente monitorados, pois podem ocasionar potenciais efeitos adversos. Desta forma, uma outra estratégia para mitigar esses comportamentos indesejáveis e evitar o uso de medicamentos, pode ser o emprego de técnicas de enriquecimento ambiental com intuito de promover o aumento da complexidade de um ambiente relativamente empobrecido nos quais os felinos domésticos vivem e em paralelo possibilitar o desenvolvimento de habilidades frente a desafios e novas experiências, evitando assim altos níveis de estresse e danos a utensílios humanos que dividem o mesmo espaço com esses animais. Como técnicas a serem aplicadas podemos dividi-las em dois aspectos, o enriquecimento permanente, como disposição de prateleiras, tocas, arranhadores de sisal, alterações físicas no ambiente de um modo geral e enriquecimento sazonal que são aquele que podem ser dispostos de forma individual ou combinada, com intuído de promover constantemente novos desafios, assimilando ao que ocorreria na natureza, como disposição de arranhado de material distinto do permanente, enriquecimento sensorial com o polvilhamento de canela em pó ou Nepeta cataria, popularmente conhecida como catnip ou erva-do-gato, caixas de papelão fechadas com petiscos dentro, dentre outras infinidades de brinquedos que hoje já se encontra disponível de forma acessível nos mercados pets. Com a associação dessas técnicas se faz possível evitar estereotipias e melhorar a qualidade de vida dos felinos domiciliados, mas é de suma importância lembrar que os felinos também demandam de outras particularidades de manejo que se não atendidas também podem levar a comportamentos indesejáveis, então é indicado adotar um manejo disponibilizando sempre uma caixa higiênica a mais do número total de gatos mantidos naquele ambiente e limpas diariamente, disponibilizar vários pontos de água para ingestão, de 2 a 3 pontos por animal e permitir rotas de fuga na chegada de visitas, priorizando disponibilidades de locais altos e ou mais penumbres. Com a adoção desse compilado de ações, certamente a relação tutoranimal melhorará consideravelmente permitindo um melhor convívio em ambiente compartilhado. 
Palavras Chaves: Manejo; Comportamentos Indesejáveis; Fármacos Alopáticos; Catnip.

\section{REFERÊNCIAS}

CARPES, Aline Zanini et al. Ferramentas para aplicação de enriquecimento ambiental para felinos cativos. 2015.

ROCHA, Rebeca da Silva. Medicina complementar e alternativa na cistite intersticial felina. 2020.

DA SILVA, Thaís Brasil Barros et al. Enriquecimento ambiental para felinos em cativeiro. Atas de Saúde Ambiental-ASA (ISSN 2357-7614), v. 2, n. 3, p. 44-52, 2015.

DAMASCENO, Juliana. Enriquecimento Ambiental para felinos em cativeiro: classificação de técnicas, desafios e futuras direções. Revista Brasileira de Zoociências, v. 19, n. 2, 2018.

MARTINS, M. F. et al. Enriquecimento ambiental como instrumento de bem-estar no abrigo municipal de gatos no município de Pirassununga, estado de São Paulo, Brasil. Revista de Educação Continuada em Medicina Veterinária e Zootecnia do CRMV-SP, v. 15, n. 1, p. 8383, 2017. 


\section{ENRIQUECIMENTO AMBIENTAL NO RECINTO DE JABUTIS-PIRANGA (Chelonoidis carbonária) DO CENTRO DE MEDICINA E PESQUISA EM ANIMAIS SILVESTRES - CEMPAS, UFMT, CUIABÁ-MT}

José Ricardo de SOUZA; Janaina Januário da SILVA; Tarcísio da Silva Santos JUNIOR; Sandra Helena Ramiro CORRÊA; e Brunna Ribeiro SILVA.

\section{Área Temática: Enriquecimento Ambiental}

O jabuti-piranga (Chelonoidis carbonaria) é um quelônio amplamente distribuído na América do Sul. No Brasil ocorre nos biomas Amazônia, Cerrado, Pantanal, Caatinga e Mata Atlântica, que correspondem, aproximadamente, a 8,4 milhões de $\mathrm{Km}^{2}$ do território nacional. O jabuti é utilizado como alimento e recurso medicinal para povos indígenas. $\mathrm{O}$ atual Centro de Medicina e Pesquisa de Animais Silvestres (CEMPAS) é uma unidade vinculada à Faculdade de Medicina Veterinária (FAVET) da Universidade Federal de Mato Grosso, Campus Cuiabá, para realização de triagem e reabilitação de animais silvestres. Além disso, outras finalidades estão relacionadas ao CEMPAS, como a educação ambiental, práticas de ensino, científica e de conservação. Dentre outras espécies da fauna silvestre do Cerrado e Pantanal, o CEMPAS abrigava um grupo de 300 espécimes de jabutis-piranga. Por meio de observações do comportamento desses jabutis, registrou-se que eles permaneciam agrupados em maior número nas laterais do recinto, distantes das áreas com radiação solar direta sobre o terreno e, por vezes, sobrepostos, como em comportamento de proteção e não de acasalamento. É sabido que a espécie, quando em vida livre, sua atividade é influenciada por fatores ambientais como temperatura e precipitação pluviométrica, se abrigando em tocas. Assim, considerando os registros do comportamento e na literatura desenvolveu-se um projeto piloto com três diferentes abrigos em madeira, com estrutura de base central, instalados no próprio recinto, sendo que, o primeiro foi construído sem cobertura e laterais abertas (SCLA); o segundo com cobertura e laterais abertas (CCLA), e o terceiro com cobertura e cortina nas laterais (CCCL). A partir da definição da faixa de horário de maior incidência solar sobre os abrigos no mês de maio, foi quantificado nesse período o número de indivíduos que se alojaram no SCLA, CCLA e CCCL. O período de maior incidência solar sobre os abrigos foi entre 15 e 17 h, ocasião em que foi registrado a presença máxima de 36 indivíduos sob o abrigo CCCL; 16 sob o abrigo CCLA e apenas um indivíduo sob o abrigo SCLA. O maior número de indivíduos buscando o abrigo com cobertura e cortina nas laterais pode indicar uma maior preferência dos jabutis por abrigos com menor luminosidade, mimetizando o comportamento natural de se abrigar em tocas. Pretende-se estender o estudo da preferência dos jabutis por abrigos com diferentes intensidades de iluminação natural ao longo das estações do ano, conforme a sazonalidade das condições ambientais no estado de Mato Grosso.

Palavras Chaves: Abrigos multifuncionais; Comportamento; Luminosidade.

\section{REFERÊNCIAS}

CORTÉS-GOMEZ, A.M.; RUIZ-AGUDELO; C.A.; VALENCIA-AGUILAR; A.; LADLE, R.J. 2015. Universitas Scientiarum, 20 (2): 229-245. Ecological functions of neotropical amphibians and reptiles: a review. 
NOSS, A.J.; MONTAÑO, R.R.; SORIA; F.; DEEM; S.L.; FIORELLO, C.V.; FITZGERALD, L.A. 2013. South American Journal of Herpetology, 8 (1), 19-29. Chelonoidis carbonaria (Testudines: Testudinidae) Activity Patterns and Burrow Use in the Bolivian Chaco.

TAVARES, A.S.; MORCATTY, T.Q.; ZUANON, J.; MAGNUSSON, W.E. 2019. Plos One, 14(2), 1-18. Influence of body size, topography, food availability and tree-fall gaps on space use by yellow-footed tortoises (Chelonoidis denticulatus) in Central Amazonia. 


\section{ENRIQUECIMENTO AMBIENTAL E FATORES QUE INFLUENCIAM O BEM-ESTAR DE SUÍNOS: REVISÃO BIBLIOGRÁFICA}

Letícia de Souza da SILVA; Suzy de Araújo ALBERNAZ; e Ailton Batista PEREIRA.

\section{Área Temática: Enriquecimento Ambiental}

A ética na produção animal busca melhorias na qualidade de vida animal e proporcionar o bem-estar animal em granjas (ABPA, 2021; FOPPA, 2014). O enriquecimento ambiental é um aperfeiçoamento das instalações e ambiente podendo melhorar o conforto, oferecendo bem-estar para os animais criados em sistemas intensivos, onde esses são criados presos em baias durante todas as fases do ciclo de vida, assim como a busca por sistemas de criações alternativos (RIBAS, 2020). São métodos que reduzem as taxas de estresse, distúrbios comportamentais, ansiedade, mortalidade e elevando taxas reprodutivas e produtivas nos plantéis (RICCI et al., 2017; FOPPA, 2014). A Instrução Normativa no 113, de 16 de dezembro de 2020 estabelece que a utilização de objetos enriquecedores como palha, feno, cordas, correntes, madeira, maravalha, borracha, plástico e metodologias sonoras, visuais e olfativas, promove um ambiente diversificado, estimulando atividades típicas da espécie como por exemplo, a investigação do ambiente (BRASIL, 2020). Segundo a literatura para marrãs fase de maternidade é eficaz o uso de palha, material esse para construção de ninhos (RIBAS, 2020; YUN, 2015; MAIA, 2013). A creche é um dos períodos mais estressante para os leitões, esses são retirados das mães aos 21 dias de vida, comprometendo ainda mais o seu bem-estar (BRASIL, 2020). Visando amenizar tal situação e otimizar o bem-estar animal, o enriquecimento ambiental tem sido a melhor alternativa atualmente empregada (FOPPA, 2014). A fase de crescimento e terminação é à saída da creche até a comercialização, onde ocorre a engorda dos leitões com 63 dias de idade pesando aproximadamente 100/120 kg, todo esse processo gera estresse para os animais, pois vivem confinados (LIMA, 2018). Como o uso enriquecimento ambiental abrange todas as fases de vida é válida sua eficácia para amenizar estereotipias nessa fase também (BRASIL, 2020). Acreditasse que o fator temperatura está diretamente relacionado ao bem-estar dos suínos, onde cada fase apresenta um conforto térmico adequado, para isso são utilizadas lâmina d'água, aspersores, ventiladores, nebulizadores, janelas e escamoteadores de acordo a necessidade de cada fase de vida (SANTOS, 2018). Dessa forma, conclui-se que o uso de objetos enriquecedores trás bem-estar positivo, fazendo com que haja comportamento natural da espécie de exploração e investigação.

Palavras Chaves: Comportamento; Intensivo Confinado; Estresse; Estereotipias.

\section{REFERÊNCIAS}

ABPA-Associação Brasileira de Proteína Animal. Relatório Anual 2021. Disponível em: http://abpa-br.org/wp content/uploads/2021/04/ABPA_Relatorio_Anual_2021_web.pdf Acesso em: 8 junho. 2021.

BRASIL. Ministério da Agricultura, Pecuária e Abastecimento. Instrução Normativa no 113 de 16 de dezembro de 2020. Estabelece as boas práticas de manejo e bem-estar animal nas granjas de suínos de criação comercial. Diário Oficial da União, edição 242, seção 1, 5p. Brasília-DF. 2020. 
FOPPA, Luciana et al. Enriquecimento ambiental e comportamento de suínos: revisão. Brazilian Journal of Biosystems Engineering, v.8, p.1-7, 2014.

FOPPA, Luciana.; PIEROZAN, Carlos Rodolfo; CALDAS, Edson; MICHELON, André. Suinocultura: uma saúde e um bem-estar. $1^{a}$ edição, Brasilia, Coordenação Editorial Assessoria Especial de Comunicação Social, 500 p. 2020.

LIMA, Adiel Vieira. Desempenho zootécnico de suínos nas fases de crescimento e terminação submetidos a diferentes programas de iluminação em ambientes climatizados. Trabalho de Conclusão de Curso (Bacharelado em Zootecnia) - Universidade Federal Rural de Pernambuco, Pernambuco. 2018.

MAIA, Ana Paula de Assis. Enriquecimento ambiental como medida para o bem-estar positivo de suínos. Revista do Centro de Ciências Naturais e Exatas, v. 14, n. 5, 2862-2877p. 2013.

RIBAS, Juliana Cristina Rego; DIAS, Cleandro Pazinato; LUDTKE, Beatriz Charli; BUSS, Lizie Pereira. Suinocultura: uma saúde e um bem-estar. $1^{a}$ edição, Brasília, Coordenação Editorial -Assessoria Especial de Comunicação Social, 500 p. 2020.

RICCI, Gisele Dela et al. Influência do treinamento de manejadores no aparecimento de lesões na cavidade bucal de leitões após pratica de desgaste de dentes. 2017. Congresso Brasileiro de Biometeorologia, Ambiência, Comportamento e Bem-Estar Animal "Responsabilidade Ambiental e Inovação". 9p. 2017.

SANTOS, Tatiany Carvalho. et al. Influência do ambiente térmico no comportamento e desempenho zootécnico de suínos. Revista de Ciências Agroveterinárias, v. 17, n. 2, p. 241 253, 2018.

YUN, Jinhyeon; VALROS, Anna. Benefits of Prepartum Nest-building Behaviour on Parturition and Lactation in Sows. Asian-Australas Journal Animal Science. v. 28, n. 11, 1519-1524p. 2015. 


\section{ENRIQUECIMENTO AMBIENTAL EM CÃES}

Jassanael Pereira SIQUEIRA.

\section{Área Temática: Enriquecimento Ambiental}

O estudo cientifico do enriquecimento ambiental teve início na década de 1960, essas técnicas vêm sendo aplicada em canis e em outras formas de cativeiro desde a década de 1970. Os cães são animais que necessitam além do contato humano, a instigação por meio do enriquecimento ambiental, nota-se que o tempo que os animais passam em casa sozinhos contribui para o aparecimento de alterações comportamentais. O estudo da etologia é fundamental para que se possa compreender o modo como os animais inter-relacionam-se com o ambiente e, então, conhecer o comportamento habitual da espécie analisada. Os procedimentos de melhoria do meio têm se concentrado em identificar, caracterizar e avaliar a importância relativa de diferentes estímulos ambientais e avaliar a importância de sua escolha, essa área do manejo animal tem como objetivo geral aumentar a qualidade de vida de animais mantidos em cativeiro. Seu uso visa incrementar o ambiente no qual um ou mais animais vivem, de modo a dar mais liberdade, capacitar e motivar os animais a expressar o seu comportamento natural, ou o mais próximo disso. As técnicas de enriquecimento ambiental podem ser divididas em cinco categorias, sendo elas: o enriquecimento físico (referente à estrutura em que o animal de situa), enriquecimento sensorial (uso dos cinco sentidos), enriquecimento cognitivo (estímulos da capacidade intelectual), enriquecimento social (interações dentro do ambiente em que o animal está situado) e enriquecimento alimentar. $\mathrm{O}$ uso regular de diversas técnicas de enriquecimento ambiental tem proporcionado aos animais um maior grau de bem-estar, melhorando sua qualidade de vida.

Palavras Chaves: Bem-Estar; Comportamento; Cães; Ambiente.

\section{REFERÊNCIAS}

SAMPAIO, Rubia et al. Behavioral assessment of shelter dogs submitted to different methods of environmental enrichment. Ciência rural, [s. 1.], 2019. DOI https://doi.org/10.1590/0103-8478cr20180181. Disponível em: https://www.scielo.br/j/cr/a/6DwCzcKJGkwXLCrd5bJkprS/?lang=en. Acesso em: 12 jun. 2021.

FOOPA, L. et al. ENRIQUECIMENTO AMBIENTAL E COMPORTAMENTO DE SUÍNOS: REVISÃO. Brazilian Journal of Biosystems Engineering, [s. 1.], 2014. DOI https://doi.org/10.18011/bioeng2014v8n1p1-7. Disponível em: https://seer.tupa.unesp.br/index.php/BIOENG/article/view/173. Acesso em: 13 jun. 2021.

GUDIEL, Caroline et al. ENRIQUECIMENTO AMBIENTAL EM CÃES: REVISÃO BIBLIOGRÁFICA. Congresso Internacional de Bem-Estar, [s. 1.], 2018. Disponível em: https://eventos.uceff.edu.br/eventosfai_dados/artigos/cibea2018/915.pdf. Acesso em: 19 jun. 2021. 
HENZEL, Marcelo. O ENRIQUECIMENTO AMBIENTAL NO BEM-ESTAR DE CÃES E GATOS. In: HENZEL, Marcelo. O ENRIQUECIMENTO AMBIENTAL NO BEM-ESTAR DE CÃES E GATOS. Orientador: Prof. Dr. André Caríssimi. 2014. Monografia (Graduação em Medicina Veterinária) - Faculdade de Veterinária, Universidade Federal do Rio Grande do Sul, [S. 1.], 2014. Disponível em:https://lume.ufrgs.br/bitstream/handle/10183/104884/000940557.pdf?sequence=1\&i sAllowed=y. Acesso em: 19 jun. 2021.

RAMOS, Tatiane. IMPACTO DO ENRIQUECIMENTO AMBIENTAL SOBRE O COMPORTAMENTO DE CÃES E DIGESTIBILIDADE DA DIETA EM CANIL EXPERIMENTAL. Veterinary Science, [s. 1.], 2020. Disponível em: https://www.researchgate.net/publication/345453051_IMPACTO_DO_ENRIQUECIM ENTO_AMBIENTAL_SOBRE_O_COMPORTAMENTO_DE_CAES_E_DIGESTIBI LIDADE_DA_DIETA_EM_CANIL_EXPERIMENTAL. Acesso em: 14 jun. 2021. 


\section{ENRIQUECIMENTO AMBIENTAL PARA GATOS DOMICILIADOS: REVISÃO BIBLIOGRÁFICA}

Valéria Smith Neves e SANTOS.

\section{Área Temática: Enriquecimento Ambiental}

Para assegurar saúde e bem-estar dos gatos, os veterinários devem orientar os tutores sobre questões médicas e preventivas, mas também, aconselhar de forma prática e adequada quanto à questão da valorização do Enriquecimento Ambiental (EA) em casa, pois ambientes estressantes podem causar doenças e problemas comportamentais. O EA se baseia na inserção e manejo de itens em um ambiente limitado e possivelmente estressante, com objetivo de promover maior bem-estar aos gatos que vivem ali, permitindo que seja exercido e estimulado seu comportamento natural como arranhar, caçar e brincar. Casas com muitos gatos precisam modificar o ambiente para garantir a sensação de segurança, embora muitos gatos possam se adaptar à convivência em grupo, eles são sensíveis ao estresse causado por fatores sociais. Para a inserção do EA, primeiro é necessário o reconhecimento da área de acesso do gato, considerando todos os moradores. É preferível que o ambiente seja livre de rotas de fuga, com uso de telas que podem ser colocadas em janelas, portas, muros e portões. As telas também são essenciais para a proteção de gatos que moram em prédios. Devem ser providenciadas diversas opções para escalar e explorar o ambiente de forma segura, criando locais elevados com prateleiras, pontes, rampas, nichos e móveis para gatos, sempre permitindo o livre acesso e também estímulos físicos. Nas janelas podem ser instaladas prateleiras e caminhas para que o gato possa observar o exterior e tomar sol. Todos esses lugares podem ser pontos de descanso e devem passar segurança e permitir que o gato observe seus arredores. Diversos arranhadores podem ser distribuídos pelo ambiente, nos pontos mais atrativos como corredores, sacadas, entradas e saídas. É indicado que sejam adequados ao gosto e tamanho do gato, podendo ser inclusive produzidos pelo próprio tutor. $\mathrm{O}$ alimento pode ser fornecido de diversas formas como alimento úmido aquecido ou congelado em cubinhos, ração ou petiscos podem ser fornecidos em tabuleiros de alimentação ou brinquedos de liberação lenta, gerando graus de complexidade para o estímulo mental. Graminhas e plantas não tóxicas podem ficar disponíveis para o gato cheirar e ingerir se desejar. As atividades pseudopredatórias podem ser realizadas em forma de brincadeiras e alimentação, permitindo que o gato adquira o alimento ativamente. A água deve estar sempre disponível em diversos pontos e também podem ser usadas fontes de água elétricas para estimular o consumo. Os pontos de alimentação e ingestão de água devem ficar longe das caixas sanitárias. Essas caixas devem ser espalhadas no ambiente, conter areia do tipo que agrade o gato, seguindo a relação adequada de caixas por gato, e dispostas em locais silenciosos para que o gato não tema usá-las. Ainda, pode ser realizado um rodízio entre os brinquedos oferecidos, para que dessa forma eles continuem atrativos. Nos momentos de maior agitação, recomenda-se aos tutores brincadeiras com os gatos utilizando varinhas lúdicas. Conclui-se que o EA é importante para promover melhora na qualidade de vida do animal, tornando-a mais prazerosa e interessante.

Palavras Chaves: Gatos; Ambiente Doméstico; Bem-Estar. 


\section{REFERÊNCIAS}

ELLIS, S.L.H. et al. 2013. AAFP and ISFM feline environmental needs guidelines. v. 15, p. 219-230.

HEATH, S.; WILSON, C. 2014. Canine and Feline Enrichment in the Home and Kennel: A Guide for Practitioners. p. 427-449.

ATKINSON, T. 2018. Practical Feline Behaviour: Understanding Cat Behaviour and Improving Welfare. Boston: Cabi, 286. 


\title{
ENRIQUECIMENTO AMBIENTAL PARA VACAS LEITEIRAS
}

\author{
Yasmin Silva de JESUS; Sandra Regina Pires de MORAES; Lucas Dourado MATOS; \\ Vitória Fernanda Ferreira da SILVA; e Ivan Ricardo Matos ESPÍNDOLA.
}

\section{Área Temática: Enriquecimento Ambiental}

O enriquecimento ambiental é baseado em melhorias físicas, sociais, alimentares entre outros que proporcionam bem-estar ao animal, reduzindo o estresse e comportamentos anormais, de forma a simular situações que podem ocorrer no ambiente, estimulando comportamentos naturais próprios da espécie. Instalações, manejo e ambiente têm grande influência na bovinocultura de leite, principalmente relacionado a produção, tendo no comportamento desses animais uma das ferramentas utilizadas para avaliar o bem-estar. Sabe-se que os bovinos são animais que formam grupos sociais e apresentam boa memória sendo capazes de identificar as pessoas envolvidas no manejo diário, tendo reações conforme a experiência vivida podendo ser negativa, como o estresse ocasionado por fatores físicos como fome e temperatura, psicológicos como contenção e medo do tratador, por exemplo. Por isso, o enriquecimento ambiental é utilizado como meio de redução do estresse através de implementação de objetos que quebram a monotonia do espaço onde vivem, como o uso de aspersores e nebulizadores de forma a amenizar o calor por meio do resfriamento corpóreo proporcionando conforto térmico e aumentando o consumo alimentar. Outra alternativa que ainda é pouco utilizada nas fazendas brasileiras é o uso da escova automática ou estacionária, que faz parte do enriquecimento ambiental físico promovendo um comportamento natural de se coçar, trazendo benefícios ao bem-estar além de manter a limpeza desse animal. O barulho típico da ordenhadeira e das portas de metais quando se abrem e fecham acarretam respostas negativas como o estresse. Um método para amenizar tal reação é a utilização da música clássica ou mais dançante na sala de ordenha como enriquecimento ambiental social e sensorial. Assim é possível obter resultados positivos quanto a um pequeno, mas significativo aumento na produção de leite e melhor condução dessas vacas até a sala de ordenha, além de redução de escore de reatividade dos animais e na porcentagem de animais positivos no teste de CMT esse tipo de enriquecimento beneficia não só a vaca, mas o ordenhador também. Além disso, é possível estimular o animal de forma criativa por meio de introdução de alimentos para que se desperte a curiosidade ocorrendo uma interação com o ambiente com o intuito de reduzir o estresse, esse tipo de enriquecimento pode ser disponibilizado por meio de cochos tipo trenó que são moveis e estimulam o animal a se locomover, suspensão de alimentos, colocando-os em redes, gaiolas ou utilizando as ferramentas disponíveis para promover esse tipo de atividade, o importante nesse quesito é sempre variar na disponibilidade dos alimentos para que essa novidade desperte a curiosidade dos animais. Introduzir técnicas de enriquecimento ambiental será benéfico não só para o animal como para o proprietário também.

Palavras Chaves: Manejo; Estresse; Bem-Estar.

\section{REFERÊNCIAS}

ABADE, C.C. Relaxar e Coçar é só Começar. Disponível em https://www.milkpoint.com.br/artigos/producao-de-leite/relaxar-e-cocar-e-so-comecar85649n.aspx. Acesso em 8 de junho de 2021. 
BETTENCOURT, A. F.; MACHADO, A. T.; LEITE, T. E.; VARGAS L. B. et al. Vacas leiteiras e música clássica brasileira: um encontro inusitado. In: ANAIS DO CONGRESSO BRASILEIRO DE ZOOTECNIA, 2017, . Anais eletrônicos... Campinas, Galoá, 2017. Disponível em: https://proceedings.science/zootec/papers/vacas-leiteiras-e-musicaclassica-brasileira--um-encontro-inusitado Acesso em: 09 de junho. 2021.

MOREZZI, B. B., Enriquecimento Ambiental em Zoológico. Disponível em https://doi.org/10.31533/pubvet.v15n05a813.1-9. Acesso em 7 de junho de 2021.

RIBEIRO, J. Enriquecimento Ambiental- Bovinos de Leite. Disponível em https://zootecniabrasil.com/2020/11/29/enriquecimento-ambiental-bovinos-de-leite/. Acesso em 7 de junho de 2021.

SANT'ANNA, A. C.; COSTA, M. J. R. P.; MADUREIRA, A. P. Boas práticas de manejo conforto vacas em lactação. Jaboticabal: Funep, 2014. E-book 39p. 


\title{
ESTEREOTIPIAS E O BEM-ESTAR EM EQUINOS ESTABULADOS
}

\author{
Yasmin Silva de JESUS; Victória Curvo ORMOND; Cely Marini Melo e OÑA; Janaina \\ Januário da SILVA; e Isabela de Mantova CORRENTE.
}

\section{Área Temática: Manejo para Bem-Estar}

O conceito de bem-estar está relacionado com qualidade de vida tal como: saúde, felicidade e longevidade, o animal precisa estar em completa harmonia físico-mental. Para o equino, o bem-estar está relacionado diretamente com suas necessidades naturais, nos primórdios o cavalo tinha vida livre e se alimentava a maior parte do tempo. Porém, com a chegada da civilização, o homem percebeu que os animais teriam serventia para diversas finalidades. Com isso o cavalo foi obrigado abandonar seus comportamentos naturais, passou a viver em baias, houve uma mudança brusca na sua alimentação, passando de uma dieta baseada totalmente em forragens, para ter uma parte substituída por concentrados ricos em energia. Objetivou-se, a partir dessa revisão, evidenciar a influência das estereotipias no bem-estar dos equinos e quais manejos devem ser adotados para minimizar seus efeitos. A estabulação dos equinos favoreceu o desenvolvimento de problemas comportamentais, devido à escassez de espaços nas baias, privação do convívio em grupo e mudança em sua alimentação, sendo estes uns dos principais fatores para o desenvolvimento de estereotipias. Respostas fisiológicas e comportamentais são desencadeadas na tentativa de atingir a homeostase, quando este equilíbrio não se estabelece, o animal entra num estado de estresse permanente, acarretando as estereotipias. Estereotipias são indesejáveis e anormais, ocorrem como forma de adaptação ao ambiente. A utilização métodos proibitivos podem gerar frustração e deprimir mais o animal. Uma maneira de reduzir esse estado de estresse é diagnosticar a causa e adotar manejos que reduzam esta condição. Com base no diagnóstico da estereotipia, devem-se adotar medidas de manejo que proporcionem bem-estar, simulando situações vivenciadas pelo animal na natureza. Devem-se adotar baias amplas, os animais devem ser soltos diariamente e, quando não for possível pela ausência de piquetes, realizar caminhadas ao passo. A dieta dos equinos deve conter uma proporção elevada de fibras em relação ao concentrado. Dietas ricas em concentrado acarretam a redução do período de ingesta dos alimentos, aumentando o período de ócio, o que pode favorecer o desenvolvimento de estereotipias. Estratégias para mimetizar o tempo em que os animais passam pastejando na natureza, como bolsas de feno, que permitem que os animais comam mais devagar ajudam a evitar estereotipias. Os equinos devem ser soltos com outros indivíduos da mesma espécie para que possam expressar seu comportamento natural. Caso não seja possível ter um contato físico, pelo menos devem manter contato visual. Quando temos a presença de uma estereotipia devemos buscar avaliar e modificar o ambiente, a rotina do animal de modo a adequar a alimentação e o trabalho. É importante ressaltar que trabalho é exercício físico, pastejar é exercício mental. As baias devem proporcionar contato visual com outros animais, sendo indicado o uso de janelas laterais onde possam visualizar outros equinos. O manejo geral como presença de camas nas baias, higiene das instalações, escovação dos animais e condições adequadas de ambiência, visando o conforto térmico, devem ser sempre priorizados. As estereotipias são um indicativo de que o manejo deve ser aprimorado, além de uma maneira que os equinos utilizam para reduzir o estresse.

Palavras Chaves: Equino; Estabulação; Estereotipias; Manejo 


\section{REFERÊNCIAS}

BIRD, J. Cuidado natural del caballo. Acanto, 2004. 206p

BROOM, D. M.; FRASER, A. F. Comportamento e bem-estar de animais domésticos. 4. ed. Barueri: Manole, 2010. 438p.

MAPA. Ministério da Agricultura, Pecuária e Abastecimento. Manual de boas práticas de manejo em equideocultura. Secretaria de Mobilidade Social, do Produtor Rural e Cooperativismo. - Brasília: MAPA/ACE/CGCS, 2017. 50 p.

MILLS, D.; NANKERVIS, K.. Comportamento equino: princípios e prática. $1^{a}$ edição. Editora Roca Ltda. São Paulo, 2005. Capítulo 10, p 181-208.

REZENDE, M.J.M.; McMANUS, C.; MARTINS, R.D.; OLIVEIRA, L.P.G.; GARCIA, J.A.S.; VOUVANDINI, H. Comportamento de cavalos estabulados do Exército Brasileiro em Brasília. Ciência Animal Brasileira, v. 7, n. 3, p. 327-337, Jul./Set. 2006.

SENAR. Serviço Nacional de Aprendizagem Rural. Equideocultura: manejo e alimentação. / Serviço Nacional de Aprendizagem Rural. - Brasília: Senar, 2018. p 120, (Coleção SENAR, 185). 


\title{
IMPRINTING HUMANO E SUAS CONSEQUÊNCIAS NO MANEJO DE AVES EM CATIVEIRO E DE VIDA LIVRE - REVISÃO BIBLIOGRÁFICA
}

\author{
Gabrielle Moura NASCIMENTO; Beatriz Domingues Bressan Lopes Guimarães VIDAL; \\ Letícia Queiroz Landim de ALMEIDA; e Karolyne Moura NASCIMENTO.
}

Área Temática: Manejo para Bem-Estar

Existem diversas formas de aprendizagens comportamentais, sendo uma delas o imprinting ou estampagem, caracterizado como processo que ocorre nos primeiros dias de vida, permitindo uma ligação entre um filhote com outro indivíduo ou objeto. O objetivo deste trabalho foi realizar uma revisão bibliográfica com informações acerca do imprinting e suas consequências no manejo de aves em cativeiro e de vida livre. Foi realizado um levantamento bibliográfico a partir de 17 artigos entre os anos de 1992 a 2020, com os termos "imprinting e bem-estar de aves" e "manejo de aves silvestres". O estudo sobre imprinting em animais começou em 1935 pelo zoólogo Konrad Lorenz, que observou que patos e gansos, ao saírem dos ovos, se identificavam com o primeiro animal que vissem, passando a segui-lo, independente da espécie, sendo este considerado um imprinting indesejado, já que os animais tendem apresentar alterações comportamentais irreversíveis. Pois em condições de normalidade, os filhotes devem ser criados pelos pais, o que permite a identificação da própria espécie, adquirindo o comportamento natural. Segundo o Manual de Atuação de Fauna, papagaios e araras criadas em cativeiros domiciliares, se apresentam solitários e despareados, perdendo o princípio básico da sua fisiologia comportamental, mesmo quando mantidos em dois animais, pois na maioria das vezes o pareamento é incorreto. Estes tendem a demonstrar hábitos de imprinting pelo proprietário, principalmente em épocas reprodutivas, como abrir e fechar de asas na presença do mesmo, podendo ser confundido como comportamento dócil. Psitacídeos quando printados tendem apresentar síndrome do comportamento destrutivo de penas também em épocas reprodutivas. Passeriformes, como Pássaro-preto (Gnorimopsar chopi) e Corrupião (Icterius jamacaii) criados em cativeiro, são os mais susceptíveis ao imprinting humano, o que ocasiona dependência, e quando reintroduzidos à natureza possuem dificuldade na socialização com outros da espécie. $\mathrm{O}$ Falcão quiriquiri (Falco sparverius) quando desenvolve imprinting o associa com alimento e na presença de pessoas, apresentam vocalização intensa e estridente. De acordo com Protocolo de Reintrodução do Cardeal-amarelo (Gubernatrix cristata), aqueles nascidos em cativeiro e destinados à soltura quando adultos devem ser criados de uma maneira que evite o imprinting com humanos. Um estudo de 2008, contradiz o que foi dito por Lorenz sobre a irreversibilidade, em que filhotes de Mandarim (Taenopygia guttata) criados por Manons (Lonchura striata), em situações de cortejamento, o realizaram em indivíduos manons. Porém, ao serem reintroduzidos com a mesma espécie por alguns meses, este padrão de cortejo foi alterado. Para minimizar o efeito do imprinting em aves para reintrodução, pode-se fazer o uso de técnicas como fantoches durante o manejo alimentar ou o alimento ser ofertado em sistemas de comedouros, sem que as aves saibam quem a alimenta. Ambas as técnicas foram utilizadas em Urubu-rei (Sarcoramphus papa (Linnaeus, 1758)), Gavião-de-penacho (Spizaetus ornatus), Suindara (Tyto furcata) e Falcão quiriquiri. Diante do exposto, mesmo sendo um assunto citado por profissionais de comportamento animal, existem poucos estudos sobre manejo e protocolos que evitem a estampagem em aves tanto de vida livre como em cativeiro.

Palavras Chaves: Falco sparverius; Estampagem; Manejo de aves; Taenopygia guttata; Tyto Furcata. 


\section{REFERÊNCIAS}

BRASIL, Instituto Chico Mendes de Conservação da Biodiversidade. Centro Nacional de Pesquisa e Conservação de Aves Silvestres (Org.). Programa de cativeiro do cardeal-amarelo (Gubernatrix cristata): protocolo de reprodução. Cabedelo - PB: Cemave/IMCBIo, 2014.

COSTA, R. Q. 2019. Síndrome do comportamento destrutivo de penas em psitacídeos. Trabalho de Conclusão de Curso em Medicina Veterinária. Universidade Federal Rural de Pernambuco, Garanhuns, 2019.

JIMENEZ, J. F. P. 2008. Comportamento de avestruzes (Struthio camelus domesticus) criados em sistemas de casais ou trios durante o descanso reprodutivo. Dissertação de Mestrado em Ciências Agrárias - Faculdade de Agronomia e Medicina Veterinária, Universidade de Brasília. Distrito Federal, 2008.

MORTARUOLO, I. O imprinting nas aves. Atualidades Ornitológicas, n.46, março/abril, 1992.

NACHTIGALL, V. M.; MENEZES, P. Q.; SILVA, T. T.; MORETTI, V. D.; MEDEIRA, U. S.; BANDARRA, P. M. Utilização de fantoche para alimentação de suindara (Tyto furcata): relato de caso. In: XXVII Congresso de Iniciação Científica. $4^{a}$ Semana Integrada da UFPEL, 2018.

NEAS, V. R. S.; RIBEIRO, C. S. Manual de atuação funcional. Ministério Público do Estado de Goiás, 2020.

TOSTES, A. P. Imprinting em aves. Atualidades Ornitológicas, n.121, 2004.

VIANNA, B.; SANTOS, F. B. Parque dos falcões: aves e humanos no espaço da linguagem. 31ํ Reunião Brasileira de Antropologia. Brasília, 2018.

YAMAMOTO, M. E.; VOLPATO, G. L. Comportamento animal. 2.ed. Rio Grande do Norte: Edufrn, 2008. 


\title{
LOBO GUARÁ, DA VIDA SELVAGEM AO CATIVEIRO: AMBIENTE ENRIQUECIDO E BEM ESTAR
}

\author{
Thiago Augusto Costa MARINS; Sandra Regina Pires de MORAES; Andressa Gabrielle \\ Barbosa BARCELOS; e Bruna Gabriela da Costa MOREIRA.
}

Área Temática: Enriquecimento Ambiental

Com o avanço da produção agrícola, o habitat natural do lobo guará (Chrysocyon brachyurus) acaba sendo destruído e a espécie corre risco de voltar a ser vulnerável. Sendo assim, com essa ameaça, torna-se essencial a criação deste animal em cativeiro. Porém, a taxa de natalidade é normal, mas a mortalidade de filhotes de até um ano é preocupante. Sendo assim, surge a necessidade de uma investigação e adequações nesses recintos de preservação. Esses recintos devem estar em consonância com a rotina natural de vida livre dos lobos, com qualidade e boas condições de bem-estar. O enriquecimento ambiental é uma alternativa muito recomendada e deve estimular o animal a sair da rotina do cativeiro, incentivar o comportamento natural pela busca do alimento, a fim de que os lobos tenham um nível de atividade com a exploração, diminuindo os efeitos de tédio da vida cativa. Para evitar estresse pelo ambiente cativo, o recinto para o lobo guará deve ter cerca de $270 \mathrm{~m}^{2}$ por animal e comumente recomenda-se a criação em trio com área do recinto de $800 \mathrm{~m}^{2}$. No recinto devem ser adicionadas vegetação, folhas secas, uma piscina para bebedouro e banhos, e troncos ocos espalhados, objetivando-se a instigação e a exploração pelos animais, de modo a simular ao máximo o ambiente natural. O enriquecimento ambiental pode ser dividido em cinco partes: alimentar, cognitivo/ocupacional, físico, sensorial e social. Assim sendo, cabe a cada instituição que cria animais em cativeiros compreender o comportamento natural e assim garantir a qualidade de vida aos lobos. De acordo com alguns pesquisadores, para elaboração de um recinto adequado é necessário considerar algumas características: tamanho, exposição, vegetação, topografia, cor do substrato, quantidade de espécimes por recinto, abrigo, forrageio, localização e atividade. O lobo guará tem entre seus alimentos, plantas nativas do cerrado, então, as espécies utilizadas para enriquecer o recinto devem ser de preferência, dessas plantas que estão presentes na alimentação natural, para que não ocorra intoxicação. Para simular um ambiente presente na savana brasileira, o local deve possuir um relevo acidentado, contendo pedras e troncos e outras estruturas para que o animal possa expressar seu comportamento natural. Para instigar o comportamento social e garantir a reprodução, pode-se recomendar a manutenção de um casal por recinto, onde os comportamentos agressivos poderão diminuir e a prole poderá ser garantida. Também existe a possibilidade de inserir outros animais, tais como antas e capivaras, para que o nicho ecológico seja garantido, ressaltando que esses animais devem ser criados juntos desde a fase inicial da vida de todos. A alimentação do lobo guará é bem variada, assim fica mais fácil enriquecer o recinto com alimentos dispersos por toda área, instigando o comportamento alimentar e sensorial, pois alguns alimentos podem conter um odor adicional e estimulando o instinto de caça. Objetivando-se evitar situações de estresse que possam prejudicar o comportamento natural desses animais, faz-se necessário o uso dos enriquecimentos ambientais citados, para que possam melhorar o bem-estar desses animais, visando consequentemente a queda do índice de mortalidade em animais filhotes de lobos guarás.

Palavras Chaves: Recintos; Comportamento Natural; Estresse; Preservação. 


\section{REFERÊNCIAS}

QUEIROZ, A. E. S.; RICCI, E. L.; BUENO, L. L.; BERNARDI, M. M.; SPINOZA, H. S.; NICOLETTI, M. A.; MUÑOZ, J. W. P.; FUKUSHIMA, A. R. Análise comparativa dos comportamentos do lobo-guará (Chrysocyon brachyurus) em cativeiro: Uma proposta de enriquecimento ambiental. Revinter, v. 12, n. 02, p. 14- 46, junho 2019. DOI: http://dx.doi.org/10.22280/revintervol12ed2.449. Acesso em 08 de junho de 2021.

TRABAJAR EN EL ZOO. Cuidados del lobo de crin. 2016. Disponível em $>$ http://www.trabajarenelzoo.com/2016/03/cuidados-del-lobo-de-crin.html $<$ Acesso em 08 de junho de 2021.

VASCONCELLOS, Angélica da Silva. Enriquecimento ambiental para o lobo guará (Chrysocyon brachyurus). 2005. 108 f. Dissertação de Mestrado - Universidade de São Paulo (USP). Instituto de Psicologia São Paulo. Acesso em 08 de junho de 2021.

VASCONCELLOS, Angélica da Silva. O estímulo ao forrageamento como fator de enriquecimento ambiental para lobos guarás: efeitos comportamentais e hormonais. 2009. Tese (Doutorado em Psicologia Experimental) - Instituto de Psicologia, University of São Paulo, São Paulo, 2009. doi:10.11606/T.47.2009.tde-30112009-095524. Acesso em: 2021-0608. 


\title{
MANEJO CLÍNICO CAT-FRIENDLY: DO PREPARO AO ATENDIMENTO DO PACIENTE FELINO
}

\author{
Danielli Souza POLONI.
}

\section{Área Temática: Manejo para Bem-Estar}

O gato é uma espécie com diversas peculiaridades fisiológicas e comportamentais, devido a isso, o conhecimento de técnicas e estratégias para a abordagem desse paciente é necessária para o seu bem-estar. O conjunto de conhecimento, manejo especializado e enriquecimento ambiental de consultórios para os felinos são denominados "Cat-Friendly". O presente resumo possui o intuito de esclarecer condutas cat-friendly para que melhor seja $\mathrm{o}$ atendimento de felinos favorecendo o bem-estar. O reconhecimento de medo e ansiedade é de extrema importância no atendimento felino, para que assim se antecipe ações que cause injúrias nos indivíduos ao redor e estresse ao animal. O status comportamental do gato se manifesta através da postura corporal e expressões faciais englobando as posições das orelhas, pupila e formato da língua. Para isso, o manejo feline-friendly (amigável para felinos) deve ser adotado a fim de gerar aprovação do proprietário, conforto ao paciente e equipe veterinária. Anteriormente ao atendimento clínico, os tutores podem tomar medidas que diminua o estresse do deslocamento a clínica, através de caixas de transportes confortáveis e uso de toalhas sobre a caixa para diminuição de ruídos. Se necessárias medicações como gabapentina podem ser administradas duas horas antes do atendimento para reduzir estresse e ansiedade. $\mathrm{Na}$ clínica, o animal deve ser direcionado a área exclusiva para felinos, proporcionando ambiente mais calmo e silencioso. Dentro do consultório, o gato deve ser sentir à vontade, a abertura da caixa durante a anamnese é recomendada para o reconhecimento do território. O consultório enriquecido ambientalmente com playground, brinquedos e odores agradáveis como Feliway proporcionam maior segurança e confiança aos felinos facilitando o atendimento. Para o atendimento, recomenda-se que a mesa seja forrada com cobertor macio preferencialmente trazido pelo tutor, resgatando a memória olfativa. O exame físico deve ser realizado de forma tranquila e onde o paciente desejar estar, a menor contenção possível é a melhor escolha, respeitando as particularidades de cada paciente. Durante as manipulações ou administrações de medicamentos os gatos devem ser distraídos com petiscos, patês e carinhos em regiões que sejam aceitas. Caso seja necessário, enrolar o gato no cobertor macio proporciona segurança e refúgio, facilitando o manejo dos mais ansiosos. Gatos que não aceitam a manipulação faz-se necessário a sedação para que não sejam gerados traumas aos tutores e pacientes. Inicialmente, a pressão sanguínea deve ser o primeiro parâmetro avaliado para que os outros procedimentos não interfiram, devido ao estresse, sempre em ambiente tranquilo e silencioso. Após a realização do exame físico, os exames laboratoriais são necessários. Na coleta do sangue a contenção aplicada deve ser mínima para que não ocorram alterações nos resultados, a posição deve ser confortável ao paciente e que não necessite de várias punções. A coleta poderá ser realizada com cateter, scalp ou seringa nas veias cefálica, jugular ou safena. Com isso, o atendimento deve englobar o entendimento e respeito pelo comportamento natural dos felinos fazendo com o que a equipe veterinária crie relação de confiança com tutor e paciente promovendo saúde e completo bem-estar durante o atendimento através de técnicas adequadas.

Palavras Chaves: Felinos; Cat-Friendly; Manejo; Atendimento; Bem-estar. 


\section{REFERÊNCIAS}

LITTLE, S. E. O gato: medicina interna. 1. ed. Rio de Janeiro: Roca, 2015.

STRACK, A. Manejo amigável de felinos domésticos: revisão de literatura. Trabalho de Conclusão de Curso (graduação em Medicina Veterinária) - Centro de Ciências Rurais, Universidade Federal de Santa Catarina. Curitibanos, p. 45. 2021. 


\title{
MANEJO DE GATOS DOMÉSTICOS EXCLUSIVAMENTE DOMICILIADOS
}

\author{
Paula Maria Santos FERREIRA; Sandra Regina Pires de MORAES; Thiago Viríssimo \\ Rocha SILVA; Andressa Gabrielle Barbosa BARCELOS.
}

Área Temática: Manejo para Bem-Estar

Com o crescente aumento do número de animais de companhia outras preocupações como seu bem-estar físico e mental começam a ser questionadas. O bem-estar em si envolve diversas áreas de conhecimentos como, a etologia, a fisiologia, a psicologia e afins, por isso os cuidados veterinários são parte integrante na qualidade vida animal, pois estes podem proporcional ambientes benéficos aos animais, além de apoiar tutores no desenvolvimento de habilidades que são caritativos para seus animais de estimação. Atualmente diversos profissionais da área encorajam os tutores de felinos a manterem seus gatos apenas dentro de casa em razão de o ambiente a ser oferecido apresenta as condições necessárias e adequadas aos seus animais. Quando se fala da criação de gatos domésticos os principais problemas podem diferir de acordo com o tipo de manejo utilizado, atualmente existe uma classificação de modos de criação, entre elas, tem-se a forma indoor ou exclusivamente domiciliado, sendo gatos totalmente confinados, onde o tutor consegue ter controle de sua alimentação e reprodução. Outra forma são os gatos domiciliados dentro e fora da residência (indoor - outdoor), esses são confinados, mas com acesso à área externa da casa. Têm-se também o modo de criação não-confinados (freeranging) gatos que possuem domicílio, porém podem acessar a rua com facilidade e por fim os gatos ferais (feral), esses não possuem nenhum tipo de controle do tutor, tanto em relação à sua alimentação, como sua reprodução e por isso estão suscetíveis a doenças e maus-tratos. Os gatos por serem muito adaptáveis conseguem manter seus comportamentos naturais mesmo em ambientes fechados, entretanto, sabe-se que os gatos são muito sensíveis às condições ambientais a que são submetidos, isto é, pequenas alterações causadas por pessoas podem levar ao surgimento de mudanças nos padrões de seus comportamentos e por isso, para eles não só a disposição de água e alimento consiste em um ambiente seguro e controlado, mas também o enriquecimento ambiental é imprescindível. Este pode ser realizado com sons, odores, mobília onde possa escalar e arranhar e brinquedos que estimule seus hábitos naturais, ajudando assim a tornar o ambiente menos previsível e reduzindo o estresse que é causado com espaço monótonos e com limitação espacial. Apesar das dificuldades apresentadas na manutenção de gatos na criação totalmente indoor, os perigos apresentados para a espécie que tem acesso a rua são diversos, entre eles a falta de manejo nutricional e assim subnutrição, maus-tratos, atropelamento, lesões por brigas com outros gatos, maior risco de contração de doenças infectocontagiosas. Portanto, fica notável as vantagens em se ter uma criação de forma indoor, visto que os gatos que possuem acesso irrestrito a rua estão expostos a diversas injurias e doenças que podem ocasionar em diversas zoonoses e prejudicando até mesmo os seres humanos. A guarda responsável juntamente com informações adequadas sobre a importância do manejo da espécie é a melhor forma de reduzir esses riscos.

Palavras Chaves: Criação, felinos, indoor, enriquecimento ambiental e etologia. 


\section{REFERÊNCIAS}

STRACK, A. 2021. Manejo amigável de felinos domésticos: Revisão de literatura. Santa Catarina, Universidade Federal de Santa Catarina. Campus Curitibanos. Medicina Veterinária.

TURNER, D. C.; BATESON, P.; BATESON, P. P. G. (Ed.). 2000. The domestic cat: the biology of its behaviour. Reino Unido, Cambridge University Press.

GRisOliO, A. P. R., de Carvalho Picinato, M. A., Nunes, J. O. R., \& Carvalho, A. A. B. 2017. O comportamento de cães e gatos: sua importância para a saúde pública. Revista de ciência veterinária e saúde pública, 4(1), 117-126p.

DANTAS, L. M. D. S. 2010. Comportamento social de gatos domésticos e sua relação com a clínica médica veterinária e o bem-estar animal. Niterói, Universidade Federal fluminense. Pós-Graduação em Medicina Veterinária Clínica e Reprodução Animal.

GENARO, G. 2005. Gato doméstico: comportamento \& clínica veterinária. MEDVEP. Rev. cient. Med. Vet, 16-22p.

ALBERTS, C. C. 1996. O comportamento de autolimpeza do gato doméstico (Felis catus) e uma proposta para usá-lo como caractere filogenético. São Paulo, 123-123p. 


\title{
MANEJO DE PORQUINHOS-DA-ÍNDIA COMO ANIMAIS DE ESTIMAÇÃO
}

Valéria Smith Neves e SANTOS.

\author{
Área Temática: Manejo para Bem-Estar
}

Os Cavia porcellus, conhecidos como porquinhos-da-índia, são animais de estimação exóticos de pequeno porte, com peso médio de aproximadamente $1 \mathrm{~kg}$, e possuem expectativa de vida em média de 4 a 8 anos, que junto com outros roedores representam em torno de $40 \%$ das espécies de mamíferos. A partir de uma Revisão Bibliográfica, este estudo objetiva destacar aspectos que favorecem o bem-estar dessa espécie. Para tanto, a saúde desses animais depende de cuidado, de dieta balanceada e de acompanhamento clínico veterinário especializado. Estudos apontam a importância de viverem em instalações adequadas, como forma de evitar o estresse, considerando que são muito susceptíveis a eventos estressantes, especialmente às mudanças ambientais como alterações no alimento, no comedouro e bebedouro, ou ainda, barulhos e movimentos bruscos que assustam essa espécie, podendo levar a acidentes. Desse modo as gaiolas devem apresentar uma estrutura apropriada, limpeza de duas a três vezes semanais, com dimensão semelhante às gaiolas de coelhos com espaço de $0,9 \mathrm{~m}^{2}$ por animal e substratos adequados. Devem ter uma frente fechada e outra com grade, para proporcionar segurança e ventilação. Também deve ser organizado na gaiola um espaço com tubos de plástico ou caixas para que possam se abrigar e se sentir seguros. $\mathrm{O}$ fundo deve ser forrado com tiras de jornal, serragem de madeira ou feno como forma de prevenção a lesões nas patas. Ademais, recomenda-se que a gaiola seja colocada em um lugar com ventilação e temperatura inferior a $30^{\circ} \mathrm{C}$, evitando a exposição a altas temperaturas. Devido sua sociabilidade natural, são animais que devem ser agregados em pares ou em grupos pequenos, ainda jovens, para evitar lutas entre si. São herbívoros e necessitam de alimentos frescos, evitando os ricos em açúcares, considerando sua tendência à obesidade, a ração comercial deve ser administrada em comedouros a fim de minimizar o desperdício, a contaminação fecal e urinária e deve ser obedecida a quantidade diária ideal indicada pelo fabricante. É fundamental que esta espécie receba uma alimentação equilibrada com suplementos, feno e vegetais desde as semanas iniciais de vida. O feno deve sempre estar disponível em grandes quantidades, sendo este importante para a saúde dos dentes, que crescem de forma contínua e que precisam ser desgastados para evitar patologias, e também auxiliam na saúde do sistema digestivo. Deve-se ter muito cuidado com mudanças na alimentação e, caso ocorra, que seja ao longo de uma semana como forma de evitar que o animal a rejeite e deixe de se alimentar, o que pode levá-lo à morte. Conclui-se que esses animais por serem exóticos necessitam de um cuidado especial considerando as suas necessidades naturais para que tenham uma vida saudável.

Palavras Chaves: Cavia porcellus; Bem-Estar; Animais Exóticos.

\section{REFERÊNCIAS}

COUTO, S.E.R. 2002. Criação e manejo de cobaias. In: ANDRADE, A.; PINTO, S.C.; OLIVEIRA, R.S. (orgs.). Animais de Laboratório: criação e experimentação. 1. ed., Rio de Janeiro: Editora FIOCRUZ, p. 71-79.

BALLARD, B.; CHEEK, R. 2017. Exotic Animal Medicine for the Veterinary Technician. 3. ed. Iowa: John Wiley \& Sons, 544p. 
LIMA, R.C.S. et al. 2019. Medicina preventiva aplicada a porquinhos-da-índia (Cavia porcellus). In: CONEXÃO UNIFAMETRO 2019. 
O USO DA CANNABIS SATIVA NO CONTROLE DE DOR E PROMOÇÃO DO BEM-ESTAR EM CÃES

Felipe José da Costa ANDRADE; Marília Gabryelle Guimarães de MACÊDO; Delcio Almeida MAGALHÃES; Gabriel Almeida de Oliveira BEZERRA; Gabriel Aquino ROCHA; e Thais Harumi KIMURA.

Área Temática: Medicina Integrativa

O CBD (Canabidiol) é um dos compostos químicos encontrados na Cannabis sativa, planta do gênero Cannabis, popularmente conhecida como maconha. O uso do CBD na clínica médica veterinária vem crescendo ao longo dos anos, diversos casos são relatados, evidenciando respostas benéficas do uso da planta em tratamentos de dor, inflamação, câncer, epilepsia e dentre outros distúrbios. Os efeitos do CBD no organismo dos animais ainda estão em fases de estudos, porém já é comprovado que no processo de estimulação dos receptores canabinóides tipo 2 ocorre a mediação na liberação de citocinas de células imunológicas, que apresentam efeito na diminuição da dor e inflamação no organismo dos animais, gerando analgesia e promoção do bem-estar. Além disso, os receptores CB1 quando ativados atuam na modulação da dor. Trabalhos já apontam para o uso benéfico do canabidiol no controle da dor em cães, sendo esse composto evidenciado como aliado na clínica veterinária, já que, a redução ou controle da dor em animais se apresenta como promoção de saúde e bem-estar ao paciente. Este trabalho tem como objetivo elucidar sobre os efeitos positivos do uso do canabidiol para controle de dor e promoção de bem-estar em cães domésticos. Para realização deste estudo foi efetuada coleta de dados nas bases de dados Scientific Eletronic Library Online e Google Acadêmico, no período de abril até junho de 2021. Uma seleção de trabalhos foi realizada, o critério de inclusão se baseou em artigos com desenvolvimento do uso do CBD no tratamento de dor em cães. Três trabalhos foram selecionados para composição dessa revisão sistemática. Martello et al. (2019) constatou que, ocorreu diminuição do quadro de dor em oito cães tratados com CBD, ocorreu também diminuição de $32 \%$ no quadro de dor em um cão de 10 anos tratado com CBD (De Álava, 2018). O óleo de CBD apresentou efeitos positivos na diminuição de escores de dor em cães, segundo estudo de Gamble et al. (2018). Os dados apresentados demonstram que o canabidiol atua com eficácia em quadros de dor em cães. Infelizmente existem poucos trabalhos disponíveis sobre o uso do canabidiol com cães, porém trabalhos disponíveis apresentam a eficácia da planta no tratamento de dor em cães. Se torna necessário o desenvolvimento de estudos futuros que comprovem a eficiência do CBD no controle da dor em cães. Espera-se que essa revisão ajude em pesquisas futuras sobre o uso do CBD no controle de dor e sua relação com a elevação de bem-estar para cães domésticos.

Palavras Chaves: Canabidiol; CBD; Plantas Medicinais; Pequenos Animais.

\section{REFERÊNCIAS}

DE ÁLAVA, Adriana Furtado. Cannabis de uso medicinal para el tratamiento de dolor crónico de un labrador retriever con osteoartrosis: relato del caso. 2019. Tese (Doutorado) - Facultad de Veterinaria, Universidad de la Republica. 
GAMBLE, Lauri-Jo et al. Pharmacokinetics, safety, and clinical efficacy of cannabidiol treatment in osteoarthritic dogs. Frontiers in veterinary science, v. 5, p. 165, 2018.

MARTELLO, E. et al. Effects on pain mobility of a new diet supplement in dogs with osteoarthritis: A pilot Study. Annals of Clinical Laboratory Research, v. 7, n. 2, p. 304, 2019. 


\title{
PAPEL DA CONSCIENTIZAÇÃO DE CRIANÇAS EM IDADE ESCOLAR NA PROMOÇÃO DE BEM ESTAR ANIMAL
}

\author{
Julia Pasa BRANDT; Vitória Souza DEBASTIANI; Isabelle Sá TEIXEIRA; e Deise \\ Dalazen CASTAGNARA.
}

\section{Área Temática: Manejo para Bem-Estar}

Desde o princípio das civilizações os animais fazem parte do cotidiano dos seres humanos (TEIXEIRA et al. 2016), sendo utilizados para trabalhos, produção alimentícia ou para companhia. Dentre os animais de companhia, destacam-se os cães e gatos (DOTTI 2014). Atualmente, animais de pequeno porte como cães e gatos, estão inseridos na maioria dos núcleos familiares, sendo considerados inclusive membros da família (DEL-CLARO et al. 2004). Devido a isso, a preocupação acerca do bem-estar destes animais está em destaque, pois estes mantêm contato físico e emocional com os seres humanos. Porém, para que esta inter-relação dos seres humanos com animais se desenvolva de forma responsável, são necessárias orientações (SANTOS et. al 2013) e para isso, médicos veterinários tem a função de assegurar a saúde humana e animal, assim como garantir o bem-estar (MOLENTO 2007). Dessa forma, discentes do curso de Medicina Veterinária da Universidade Federal do Pampa deram início a um projeto de conscientização e sensibilização sobre posse responsável e bemestar animal no município de Uruguaiana no Rio Grande do Sul. O município em questão apresenta um grande número de animais errantes que são consequência da baixa conscientização da população sobre posse responsável. O projeto abrangeu escolas da rede pública e privada, sendo direcionado para crianças em idade escolar devido estarem em fase de formação da sua personalidade. Além disso, crianças tendem a compartilhar seus aprendizados em suas residências com familiares e com vizinhos, permitindo assim que a informação seja implantada gradativamente na sociedade (DIAS et al 2012). As ações do projeto foram planejadas e estruturadas com auxílio de uma psicóloga e uma pedagoga da universidade, contendo linguagem e dinâmicas adaptadas para a faixa etária das crianças, sendo realizadas apresentações de slides com animações e conteúdos audiovisuais, somados a brincadeiras interativas em período pré-pandemia. Para avaliação do conhecimento das crianças sobre o bem-estar animal foram entregues formulários no momento inicial da abordagem, contendo 10 questões que abordaram o manejo alimentar, sanitário e comportamental dos animais. Após a aplicação, foram realizadas palestras educativas com intuito de elucidar cada pergunta feita anteriormente, possibilitando dessa forma a ampliação dos conhecimentos dos ouvintes. Encerrando as explanações, os questionários contendo as mesmas questões foram novamente aplicados, possibilitando a posterior comparação do entendimento das crianças antes e depois das ações do projeto. O projeto abrangeu oito escolas, sendo duas da rede privada e seis da rede pública, contando com um público total de 332 crianças. Deste total, $85,72 \%$ asseguraram ter animais de estimação. Com o índice alto de crianças com animais de estimação em casa, reforça-se a necessidade das informações corretas sobre o bem-estar destes animais. Além dessas informações, vale ressaltar a questão sobre zoonoses, onde houveram resultados discrepantes na comparação das respostas: antes da conscientização $84,81 \%$ das crianças responderam não saber o que eram zoonoses em comparação com $90,91 \%$ das crianças que responderam claramente o que são zoonoses após as explicações dos acadêmicos. Portanto, nota-se a importância da utilização de ferramentas audiovisuais para a capacitação de crianças sobre posse responsável e bem-estar animal.

Palavras Chaves: Posse Responsável; Orientação; Bem-Estar; Animais; Crianças. 


\section{REFERÊNCIAS}

BORTOLOTI, R.; D'AGOSTINO, R. G. Ações pelo controle reprodutivo e posse responsável de animais domésticos interpretadas à luz do conceito de metacontingência. Revista Brasileira de Análise do Comportamento, vol. 3, n. 1, p. 17-28, 2012.

DA SILVA, M. N. G., DE ARRUDA MISTIERI, M. L., JÚNIOR, W. d. S. F., CENTENO, L. V. P., DA EXALTAÇÃO PASCON, J. P., LUBECK, I., DUARTE, C. A., PEREIRA, D. T. P., DO PRADO, L.M. and WEILER, T. Projeto "melhor amigo" na conscientizaçõ da guarda responsável de animais de estimação. Revista Ciência em Extensão, v. 9, n. 3, p. 43$52,2013$.

DEL-CLARO, K.; PREZOTO, F.; SABINO, J. Comportamento animal. Uma introdução à Ecologia Comportamental. Jundiaí: Livraria Conceito, 2004, p. 11-15.

DIAS, I. C. L.; GUIMARÃES, C. A.; MARTINS, D. F.; BRANDÃO, V. M.; DA SILVA, I. A.; SILVA, M. I. S. Zoonoses e posse responsável: percepção e atitudes entre crianças do ensino fundamental. Revista Ciência em Extensão, v. 8, n. 2, p. 66-76, 2012.

DOTTI, J. Terapia \& animais. 1.ed. São Paulo, 2014. 294p.

MOLENTO, C. F. M. Bem-estar animal: qual é a novidade. Acta Scientiae Veterinarie, v. 35, n. 2, p. 224-226, 2007.

NOLTE, D. L.; R. HARRIS. As crianças aprendem o que vivenciam. 1.ed. Rio de Janeiro, 2009. 144p.

TATIBANA, L. S.; COSTA-VAL, A. P. Relação homem-animal de companhia e o papel do médico veterinário. Revista Veterinária e Zootecnia em Minas. v. 11, n. 103, p. 12-18, 2009.

TEIXEIRA, G. N. R. D. F.; SILVA, J. A. M. C.; SOARES, D. F. d. M. Acumuladores de animais. Cadernos Técnicos de Veterinária e Zootecnia, Minas Gerais, n. 83, p. 60-69, 2016.

SANTOS, E. M. S. et al. Educação ambiental e posse responsável de animais domésticos no combate à leishmaniose no município de Araçuaí, MG. Periódicos UDESC. 2013. 


\section{PRÁTICAS PARA GARANTIR O BEM-ESTAR DE GATOS NO ATENDIMENTO VETERINÁRIO}

Valéria Smith Neves e SANTOS.

\section{Área Temática: Manejo para Bem-Estar}

É crescente o número de lares que escolhem ter gatos como animais de estimação. Fato que pode estar ligado ao novo estilo de vida da sociedade que mora em domićlios cada vez menores. Em consequência, também se percebe aumento nos atendimentos de gatos na rotina veterinária. Porém, muitos médicos veterinários ainda não sabem lidar com as particularidades dessa espécie, que necessita de atendimento diferenciado dos cães, pois são altamente influenciados pelo ambiente, podendo sofrer com estresse agudo e medo durante as visitas ao veterinário. Assim, indica-se algumas técnicas e modificações no ambiente, baseadas em uma Revisão Bibliográfica, que facilmente podem ser adotadas pelos estabelecimentos veterinários, a fim de garantir um melhor atendimento e o bem-estar desses pacientes. O cuidado com o gato começa antes de o tutor levá-lo a clínica. Os tutores devem ser orientados quanto ao tipo ideal de caixa de transporte, de preferência aquelas que podem separar a parte superior da caixa. O gato deve estar familiarizado com sua caixa e ter livre acesso a ela em casa. Dentro da caixa deve ir junto do gato um pano com seu cheiro ou do tutor. Também podem ser levados seus brinquedos preferidos e um alimento específico para comer durante as consultas como reforço positivo. As caixas devem ir cobertas com um pano para minimizar as influências ambientais visuais. Se for transportado de carro, pode ser borrifado no interior o análogo sintético do feromônio facial felino (F3), 15 minutos antes da viagem, e o tutor também pode colocar para reproduzir músicas específicas para gatos. Há estudos que comprovam que o uso do feromônio F3 e dessas músicas, auxiliam na diminuição do estresse. Esse feromônio também pode ser usado nas clínicas em forma de difusor. A clínica pode agendar o atendimento dos gatos em um horário ou dia diferente dos cães, ou criar uma entrada, recepção e consultório específicos para essa espécie. Em todos os cômodos deve-se priorizar o silêncio, podendo colocar um aviso na recepção com esse alerta. Pode ser fabricada uma "estante" com divisórias, para que os tutores coloquem as caixas de transporte, onde em cada espaço fica uma caixa, evitando o contato direto entre os gatos. Na consulta, não é indicado retirar o gato à força de dentro da caixa, por isso é importante que seja possível desacoplar a parte superior. Os exames devem ser realizados onde o gato se sentir mais à vontade, seja dentro da caixa ou no colo do tutor. Não é indicado realizar a contenção apertando a pele da nuca, pois poderá gerar ainda mais medo e estresse. Para a coleta de sangue, o gato pode ser enrolado em uma toalha, sem apertar, ou colocá-lo sob ela, deixando apenas o membro necessário do lado de fora. Todos os itens para procedimentos devem estar à mão, para evitar o entra e sai de pessoas na sala. A adoção desses procedimentos é importante, pois além de garantir o bem-estar, evita alterações em parâmetros clínicos e laboratoriais causadas pelo estresse.

Palavras Chaves: Gatos; Ambiente Clínico; Manejo; Estresse. 


\section{REFERÊNCIAS}

RODAN, I. et al. 2011. AAFP and ISFM feline-friendly handling guidelines. v. 13, n. 5, p. 364-375.

ATKINSON, T. 2018. Practical Feline Behaviour: Understanding Cat Behaviour and Improving Welfare. Boston: Cabi, 286p.

LLOYD, J.K.F. 2021. Minimising Stress for Patients in the Veterinary Hospital: Why It Is Important and What Can Be Done About It. v. 4, n. 22, p. 1-19.

RIEMER, S. et al. 2021. A Review on Mitigating Fear and Aggression in Dogs and Cats in a Veterinary Setting. v. 11, n. 1, p. 1-27. 


\section{CRIAÇÃO INDOOR DE GATOS}

Acácia da Vitória BARRETO; e Karina Carneiro SANTOS.

\section{Área Temática: Manejo para Bem-Estar}

O número de gatos domésticos em todo o mundo está aumentando dramaticamente a cada ano. Por serem animais pequenos, silenciosos e higiênicos, os gatos podem se adaptar bem ao estilo de vida agitado das grandes cidades como, por exemplo: tempo e residências menores. A expressão Criação Indoor de gatos significa manter os gatos em casa, sem acesso livre à rua para os tão conhecidos "passeios". Ė de suma importância a conscientização de tutores, gatis, ONGS e futuros tutores para com a Criação Indoor de gatos, como meio de prevenir inúmeros malefícios que a rua pode trazer aos animais e humanos diretamente e indiretamente. Em alguns países da Europa e dos Estados Unidos, o número de gatos ultrapassa o de caninos. No Brasil, o último censo realizado em 2015 mostrou que o país possui a segunda maior população de animais de estimação do mundo, com 22,1 milhões de gatos e 52,2 milhões de cães. No entanto, apesar desse grande número, isso não significa que a qualidade de vida dos gatos domésticos seja adequada ao seu bem-estar. Sendo vistos como animais livres e caçadores, os gatos passam a falsa visão para os humanos de que eles sabem lidar com as situações encontradas fora do seu domicílio, mas não é isso que acontece, portanto, é preciso a disseminação de informação frisando que a rua nunca será o local ideal para esses animais. Os acessos às ruas desses animais podem ocasionar atropelamento, brigas territoriais com outros animais, maus tratos, acasalamentos indesejáveis gerando superpopulações, adquirir e transmitir doenças genéticas ou doenças de caráter zoonótico, ou não, transmissíveis por vírus, fungos, bactérias e protozoários. Com ênfase nesse trabalho destacamos o Vírus da Imunodeficiência Felina (FIV), Leucemia Viral Felina (FELV) e Peritonite Infecciosa Felina (PIF), sendo patogenias facilmente transmissíveis através do contato com saliva, arranhões, urina e fezes de outro animal, porém ambas não possuem cura e sim controle dos sinais. A falta de testagem e a não vacinação dos gatos acaba tornando mais dificultoso o controle já que muitos dos sinais podem só surgir após anos no animal, ou seja, o gato infectado com o vírus pode se tornar um vetor das doenças para outros gatos. A mortalidade dos animais infectados é alta podendo chegar a $80 \%$ após 3 anos. A Imunodeficiência Felina e a Peritonite Infecciosa Felina não possuem profilaxia vacinal então sua principal prevenção é o não acesso às ruas evitando assim o contato com gatos infectados. Para garantir o bem-estar dos gatos com criação Indoor é primordial deixar o lar onde eles vivem repleto de atividades voltadas para as características comportamentais do animal, criando um ambiente dinâmico, complexo e interativo que proporcione desafios físicos e mentais.

Palavras Chaves: Criação Indoor, FELV; FIV; PIF.

\section{REFERÊNCIAS}

BARRETO, V. A.; SOUZA, C. M.; CARNEIRO, K.S.; BATISTA, R.R.; SANTOS, R.R. Projeto de Extensão: Criação Indoor de Gatos. Aracaju -SE. 2019. 
GONÇALVES, Rayane. Vírus da imonudeficiência felina e vírus da leucemia felina. Uniceplac, 2019.Disponivel em:https://dspace.uniceplac.edu.br/bitstream/123456789/203/1/Rayane_ Gon\%C3\%A7alves_0002586.pdf. Acesso em junho de 2021.

BRASIL, Gatos: criação indoor. Disponível no link https://caocidadao.com.br/dicas/gatoscriacao-indoor/. Acesso em junho de 2021. 


\section{ABRIGOS COM DIFERENTES COBERTURAS PARA CATETOS (Pecari tacaju) DO CENTRO DE MEDICINA E PESQUISA EM ANIMAIS SILVESTRES (CEMPAS), UFMT, CUIABÁ-MT}

Janaina Januário da SILVA; José Ricardo de SOUZA; Sandra Helena Ramiro CORRÊA; Brunna Ribeiro SILVA; e Maria Gabriela Rossetti ROGERIO.

\section{Área Temática: Enriquecimento Ambiental}

O Centro de Medicina e Pesquisa de Animais Silvestres (CEMPAS) é uma unidade vinculada à Faculdade de Medicina Veterinária (FAVET) da Universidade Federal de Mato Grosso, Campus Cuiabá, para realização de triagem e reabilitação de animais silvestres. Além disso, outras finalidades estão relacionadas, como a educação ambiental, práticas de ensino, científica e de conservação. Muitos espécimes de aves, mamíferos e répteis estão abrigados no CEMPAS, dentre eles, uma vara com mais de 80 Pecari tajacu, conhecido comumente como cateto, muito típico no Pantanal Mato-grossense. O recinto dos catetos era o que mais concentrava espécimes numa área totalmente descoberta, sem refúgio ou sistema de cambiamento, ficando diretamente expostos às variáveis ambientais. Logo, o espaço constituiu num meio ideal para avaliarmos os efeitos do enriquecimento ambiental sobre o conforto térmico (VIEIRA \& SILVA, 2013), uma vez que na região, no período da primavera-verão, a temperatura supera os $35^{\circ} \mathrm{C}$, e no período de outono-inverno, com redução das chuvas, ocorrem dias com temperatura acima dos $40^{\circ} \mathrm{C}$ (PAZINI et al., 2020). Em função disso, foram construídos abrigos de $2,5 \mathrm{~m}^{2}$ de área e $1,80 \mathrm{~m}$ de pé direito; com estrutura de madeira; as laterais abertas e três diferentes materiais na cobertura: madeira (CM), telha de amianto (CT) e palha de Mauritia flexuosa (CP), conhecido como buriti. Todos os abrigos foram construídos em duplicata. A construção dos mesmos se deu no período de agosto à novembro de 2020 e, logo após a finalização, os catetos iniciaram a habituação dos mesmos. Com base nesse registro, propôs-se estudar, qual o tipo de abrigo mais buscado pelos catetos no período do dia com temperatura mais elevada (13 h às $16 \mathrm{~h}$ ). Para tal, as observações foram realizadas durante os meses de dezembro de 2020 à março de 2021, em semanas não consecutivas, abrangendo toda a estação de verão. Com auxílio do termômetro de infravermelho, no horário das $14: 30 \mathrm{~h}$, foram medidas as temperaturas das diferentes coberturas, sendo registrados $54{ }^{\circ} \mathrm{C} ; 47,7{ }^{\circ} \mathrm{C}$ e $43,7{ }^{\circ} \mathrm{C}$, para os abrigos com CT, CM e CP, respectivamente. Os catetos mostraram maior aceitação pelo abrigo com $\mathrm{CP}$, sendo que o número máximo de indivíduos registrados sob este tipo de cobertura foi igual a 20, densidade populacional que ocupou $100 \%$ da área de sombra projetada pelo abrigo. Este registro foi feito no período das 14:30 h às 15:00 h, do dia de observação, em fevereiro de 2021; enquanto que, no mesmo momento de observação, registrou-se seis indivíduos sob o abrigo com CM e apenas três indivíduos sob o abrigo com CT. Acredita-se que a maior aceitação dos catetos pelo abrigo com CP esteja relacionada, não apenas pelo maior conforto térmico proporcionado pelo material, mas também pela semelhança do abrigo com seu ambiente natural. Pretende-se estender o estudo da preferência dos catetos por abrigos com diferentes materiais na cobertura ao longo das demais estações do ano, conforme a sazonalidade das condições ambientais no estado de Mato Grosso.

Palavras Chaves: Abrigos multifuncionais; Conforto térmico; Madeira; Palha; Telha. 


\section{REFERÊNCIAS}

PAZINI, P.P.P.; MARTINEZ, D.T.; CALDEIRA, S.F.; et al. Green Area in Urban Cuiabá: The Case of the Universidade Federal do Mato Grosso. Floresta e Ambiente, v. 27, n.4, 2020.

VIEIRA, F. \& SILVA, I.J.O. Ambiência não é bem-estar animal. 2013. Disponível em: https://www.milkpoint.com.br/artigos/producao/ambiencia-nao-e-bemestar-animal83143n.aspx. Acesso em: 04 de novembro de 2021. 


\section{USO DO ÓLEO DE CBD E THC (FULL SPECTRUM) COMO TERAPIA INTEGRATIVA NO TRATAMENTO DE SEQUELA DE CINOMOSE EM CÃO: RELATO DE CASO}

Gustavo Sá de CARVALHO; Liz Oliveira MENEZES; Maria Yasmim Florentino dos SANTOS; e Yade Farias NUNES.

\section{Área Temática: Medicina Integrativa}

A Cannabis Sativa é uma planta utilizada há milhares de anos para fins recreativos e medicinais ${ }^{1}$. Também chamada de maconha, ela detém em sua estrutura mais de 100 compostos, incluindo o Canabidiol (CBD) e o Tetrahidrocanabinol (THC), que atuam no sistema endocanabinoide: um regulador fisiológico composto de receptores e ligantes endógenos, responsáveis pela homeostase neuronal ${ }^{1}$. Os animais, que também dispõem de um sistema endocanabinóide, podem ser amplamente beneficiados pelo uso medicinal da Cannabis ${ }^{2}$. Visto a importância do uso medicinal desta planta na veterinária, será relatado o caso de uma cadela com sequelas de Cinomose submetida a terapia integrativa com uso de óleo de CBD e THC (Full Spectrum). Trata-se de uma paciente da espécie canina, fêmea, sem raça definida, com um ano de idade, apresentando espasmos musculares. A tutora relatou que o animal tinha se recuperado recentemente da Cinomose; todavia, ainda apresentava mioclonia, sequela decorrente da doença, e a partir dos sete meses de idade manifestava crises epilépticas (chegou a ter 30 vezes em um dia). No tratamento com o primeiro médico veterinário, foi realizada a castração, devido à suspeita clínica de alteração hormonal, e foi prescrito Fenobarbital. Contudo, o animal apresentou recidivas e a dosagem do fármaco foi aumentada; além disso, a cadela fez a utilização de Diazepam. Foi iniciado o uso do Brometo de Potássio, na tentativa de cessar as crises que sempre retornavam. As convulsões persistiram por meses apesar do tratamento alopático, então a tutora decidiu buscar por serviço médico veterinário especializado em terapia integrativa. Desta feita, foi prescrito o Óleo Blend Full Spectrum CBD: THC (4000mg:1,8mg) com dose inicial de $1 \mathrm{mg} / \mathrm{kg}$, que foi sendo ajustada até chegar à dose de $3 \mathrm{mg} / \mathrm{kg}$. Concomitantemente, foi realizado o desmame dos outros medicamentos. Inicialmente, houve a redução da dose do Brometo, até a sua retirada completa e posteriormente a redução da dose de Fenobarbital. Ao decorrer do tratamento com o óleo, foram observados aspectos fisiológicos e neurológicos, onde nos primeiros dias (adaptação), observou-se sonolência, pouca sociabilidade e tontura; contudo, após a primeira administração do óleo a paciente apresentou apenas uma crise convulsiva no intervalo de 12 dias. Com o passar dos dias, a sonolência reduziu, o animal voltou a ter uma boa socialização e não apresentou mais tonturas, zerando as crises convulsivas. Diante dos aspectos positivos trazidos pelo tratamento integrativo com óleo de CBD e THC, conclui-se que o uso da Cannabis na medicina veterinária é de suma importância, visto que melhora a qualidade de vida dos animais que a utilizam, reduzindo o sofrimento e trazendo uma forma mais natural de tratamento.

Palavras Chaves: Endocanabinoide; Homeostase; Canino. 


\section{REFERÊNCIAS}

MECHOULAM, Raphael; BURSTEIN, Sumner H. Marijuana: Chemistry, Pharmacology, Metabolism and Clinical Effects. Contributors-SH Burstein [And Others]. Academic Press, 1973.

DE BRIYNE, Nancy et al. Cannabis, Cannabidiol Oils and Tetrahydrocannabinol-What Do Veterinarians Need to Know?. Animals, v. 11, n. 3, p. 892, 2021. 


\section{SOBRE OS ORGANIZADORES}

\section{FELIPE JOSÉ DA COSTA ANDRADE}

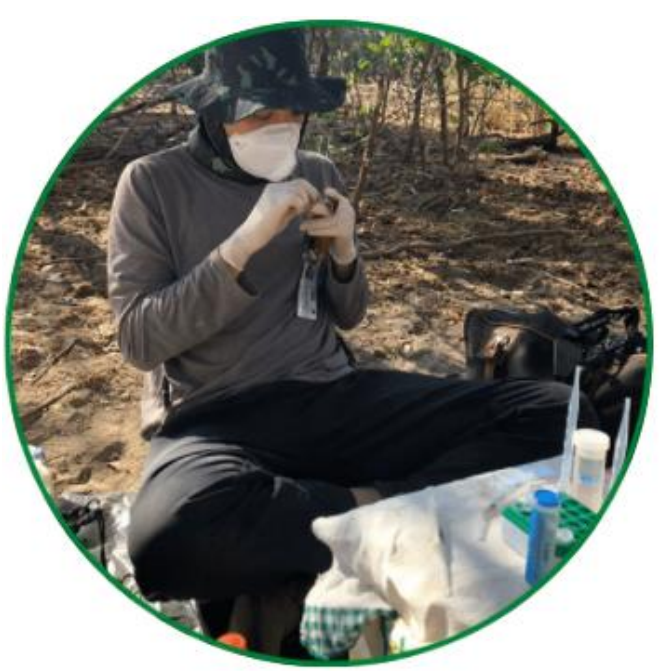

Pesquisador no West Nile Fever Project - Vigilância Epidemiológica da Febre do Nilo e demais arboviroses. Presidente do Instituto Irerê: Estudantes pela medicina da conservação. Voluntário do Programa de Estudo Manejo Conservação do Bicho-preguiça (PEMCBP). Acadêmico de Medicina Veterinária da Universidade Federal do Piauí (2017), fez parte da Diretoria Executiva do Grupo de Estudos de Animais Selvagens do Brasil - GEAS BRASIL (2019-2020), Ex-Presidente e membro efetivo do Grupo de Estudos em Biodiversidade GBIO (2019), Presidente do Centro Acadêmico de Medicina Veterinária - UFPI/ CPCE (2019), Diretor de Parcerias do Grupo de Estudos de Animais Selvagens - GEAS UFPI/TERESINA (2019), Diretor de Projetos e Difusão do Grupo de Estudos em Reabilitação Animal - REABVET (2019), Membro Efetivo do Grupo de Gestão Ambiental - GGA (2020). Possui linhas de pesquisa em Conservação, Clínica e Manejo de Animais Silvestres, Agroecologia, Educação Ambiental, Medicina Integrativa, Medicina da Conservação e Saúde Única, Literatura Educacional e Leptospirose em Animais Domésticos e Silvestres.

CV Lattes: http://lattes.cnpq.br/6279033074483233 


\section{LEONARDO DA VINCI BOGÉA CONCEIÇÃO}

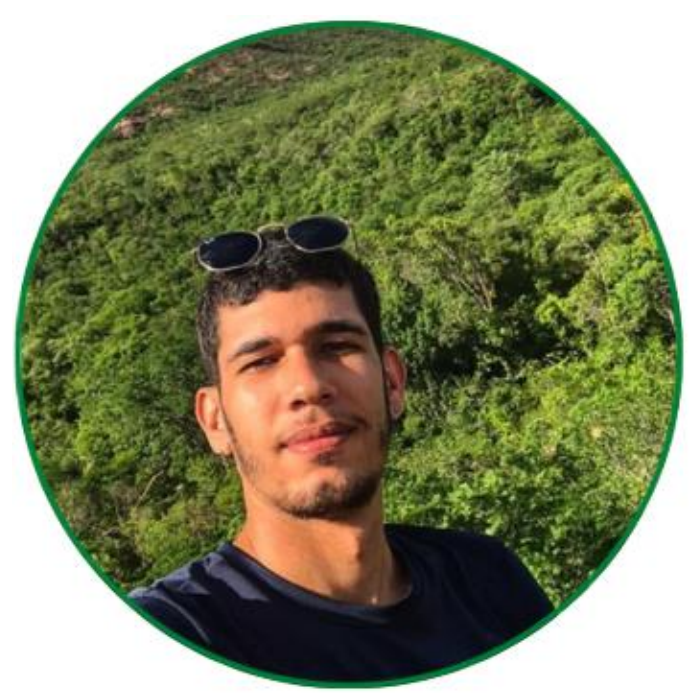

Acadêmico de Medicina Veterinária (Bacharelado) pela Universidade Federal do Piauí UFPI, Campus Professora Cinobelina Elvas - CPCE (2017). Técnico em Agropecuária pelo Instituto Federal de Educação, Ciência e Tecnologia do Maranhão - IFMA (2011-2013). Diretor Financeiro da Empresa União Veterinária Júnior - Univet Jr. (2020). Editor de Mídia do Jornal Acadêmico Ô Sabiá - UFPI/CPCE (2019). Foi monitor da disciplina Parasitologia Veterinária (2019.2).

CV Lattes: http://lattes.cnpq.br/8887448993010809

\section{JULIANA MENDES VIEIRA}

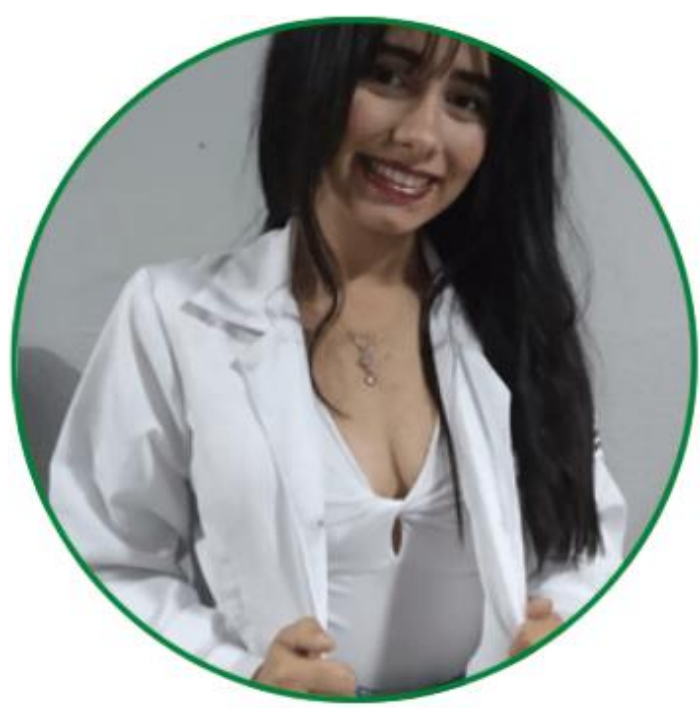

Graduanda de Medicina Veterinária ( $5^{\circ}$ Período) no Centro Universitário ICESP de Brasília. Integrante do Grupo de Estudos de Bovinocultura - GPBOV do Centro Universitário ICESP de Brasília. Integrante do Grupo de Estudos de Animais Silvestres e Exóticos GEASE- ICESP. Participa do Projeto Aves da Janela de Monitoramento de Aves Urbanas 
em parceria da Universidade de Brasília e Universidade Católica. Faz parte da equipe de comunicação e ativismo do Instituto Verdeluz. Participa do Instituto Irerê de Educação em Medicina da Conservação e Saúde Única. Presta trabalho voluntário em abrigos de cães e gatos em Brasília. Integrante do Instituto Floresça Cerrado. Desenvolve trabalhos de divulgação científica em redes sociais, plataformas digitais, e podcasts. Possui experiência na área de comportamento animal e adestramento de cães. Autora do E-book Bem-Estar em abrigos.

CV Lattes: http://lattes.cnpq.br/5906747436288342

\section{THAIS HARUMI KIMURA}

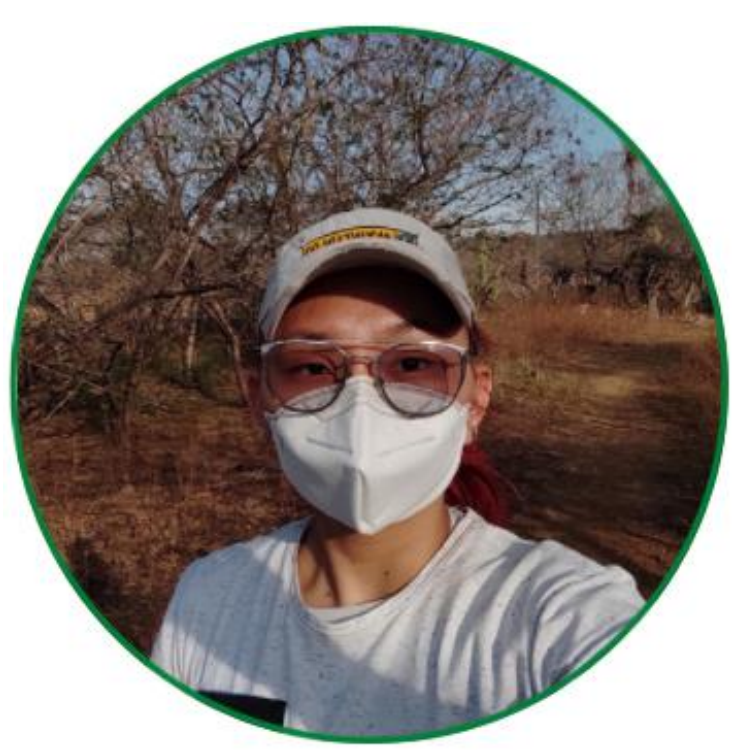

Vice-presidente do Grupo de Estudos em Animais Selvagens - GEAS UFPI/TERESINA. Bolsista PIBEX/UFPI do Projeto de Atendimento clínico-ambulatorial de Animais Silvestres e exóticos no Hospital Veterinário Universitário "Médico Veterinário Jeremias Pereira da Silva". Voluntária do Projeto Zika Zoo. Acadêmica de Medicina Veterinária da Universidade Federal do Piauí (2018). Foi membro organizadora do Projeto COVID-19: Plataformas digitais como ferramenta para o estudo - uma resposta ao enfrentamento da pandemia da UFPI (2020), Ex-diretora de mídias do Grupo de Estudos em Animais Selvagens - GEAS UFPI/TERESINA (2020-2021), Ex-diretora de Mídias do Instituto Irerê: Estudantes pela medicina da conservação (2021). Possui linhas de pesquisa em Clínica e Manejo de Animais Silvestres.

CV Lattes: http://lattes.cnpq.br/2937662890337902 


\section{GABRIEL VINICIUS CARVALHO DE LUCENA}

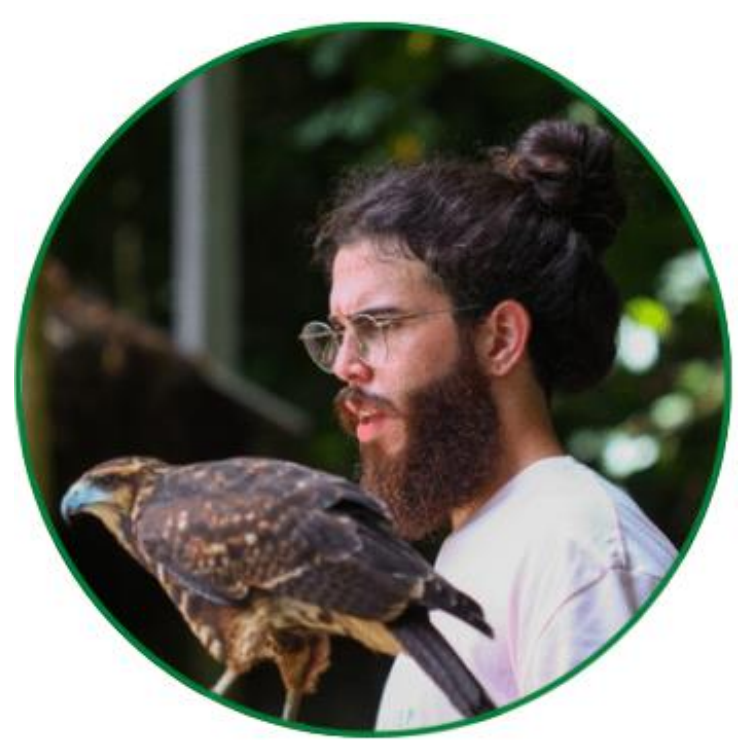

Graduando em Medicina Veterinária pela Universidade Federal de Campina Grande, no campus Centro de Saúde e Tecnologia Rural (CSTR-UFCG). Técnico em Aquicultura (2017) formado pela Escola Agrícola de Jundiaí, Universidade Federal do Rio Grande do Norte (EAJ-UFRN). Membro da diretoria do Grupo de Estudos em Animais Selvagens da UFCG (GEAS-UFCG) ocupando o cargo de Presidente. Membro da Associação de Falcoaria do Rio Grande do Norte (AFARN). Possui experiências em manejo e cultivo de organismos aquáticos e afinidade por manejo e medicina de animais silvestres e exóticos, técnicas de falcoaria e enriquecimento ambiental.

CV Lattes: http://lattes.cnpq.br/2795820000194401 


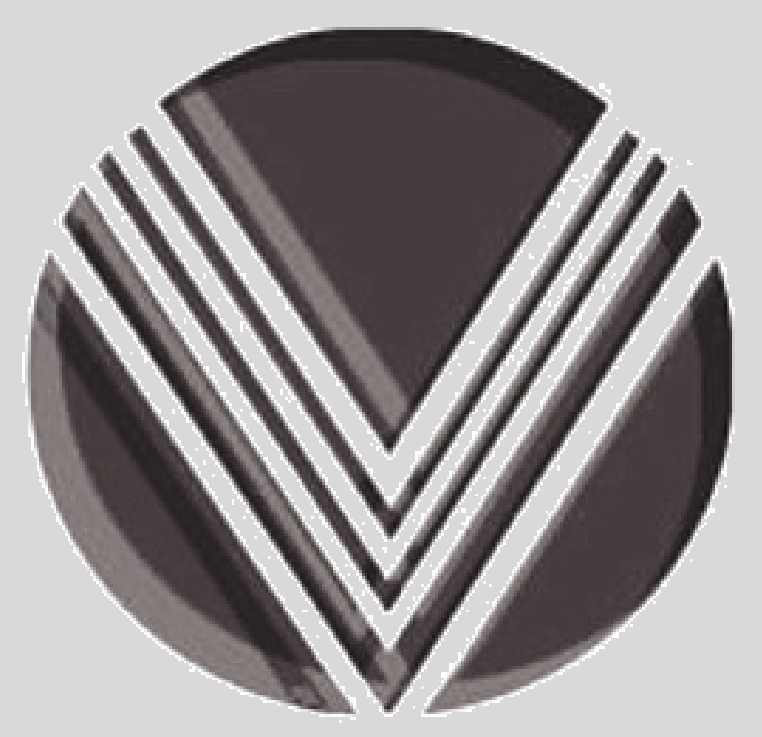

EDITORA
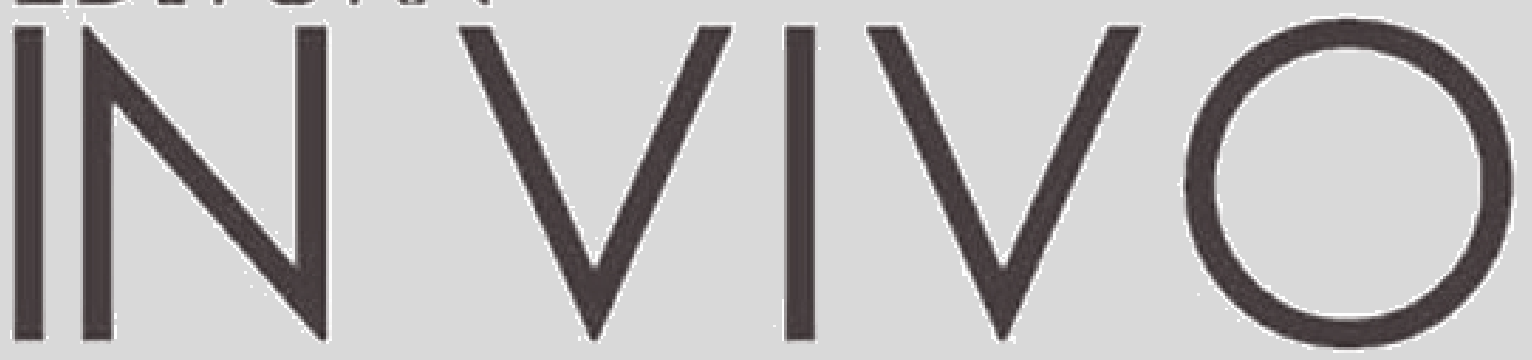

ACESSE:

www.editorainvivo.com

Juntos Somos + 